\title{
Investigation of aged Asian dust particles by the combined use of quantitative ED-EPMA and ATR-FTIR imaging
}

\author{
Y.-C. Song ${ }^{1}$, H.-J. Eom ${ }^{1}$, H.-J. Jung ${ }^{1}$, M. A. Malek ${ }^{1}$, H. K. Kim ${ }^{1}$, H. Geng ${ }^{2}$, and C.-U. Ro ${ }^{1}$ \\ ${ }^{1}$ Department of Chemistry, Inha University, 253, Yonghyun-dong, Nam-gu, Incheon 402-751, Korea \\ ${ }^{2}$ Research Center of Environmental Science and Engineering, Shanxi University, Taiyuan 030006, P.R. China
}

Correspondence to: C.-U. Ro (curo@inha.ac.kr)

Received: 10 September 2012 - Published in Atmos. Chem. Phys. Discuss.: 17 October 2012

Revised: 11 February 2013 - Accepted: 11 March 2013 - Published: 27 March 2013

\begin{abstract}
In our previous works, it was demonstrated that the combined use of quantitative energy-dispersive electron probe X-ray microanalysis (ED-EPMA), which is also known as low- $Z$ particle EPMA, and attenuated total reflectance Fourier transform infrared spectroscopy (ATRFTIR) imaging has great potential for a detailed characterization of individual aerosol particles. In this study, extensively chemically modified (aged) individual Asian dust particles collected during an Asian dust storm event on 11 November 2002 in Korea were characterized by the combined use of low- $Z$ particle EPMA and ATR-FTIR imaging. Overall, 109 individual particles were classified into four particle types based on their morphology, elemental concentrations, and molecular species and/or functional groups of individual particles available from the two analytical techniques: Ca-containing (38\%), $\mathrm{NaNO}_{3}$-containing $(30 \%)$, silicate $(22 \%)$, and miscellaneous particles $(10 \%)$. Among the $41 \mathrm{Ca}$-containing particles, 10, 8, and 14 particles contained nitrate, sulfate, and both, respectively, whereas only two particles contained unreacted $\mathrm{CaCO}_{3}$. Airborne amorphous calcium carbonate (ACC) particles were observed in this Asian dust sample for the first time, where their IR peaks for the insufficient symmetric environment of $\mathrm{CO}_{3}^{2-}$ ions of ACC were clearly differentiated from those of crystalline $\mathrm{CaCO}_{3}$. This paper also reports the first inland field observation of $\mathrm{CaCl}_{2}$ particles probably converted from $\mathrm{CaCO}_{3}$ through the reaction with $\mathrm{HCl}(\mathrm{g})$. $\mathrm{HCl}(\mathrm{g})$ was likely released from the reaction of sea salt with $\mathrm{NO}_{\mathrm{x}} / \mathrm{HNO}_{3}$, as all 33 particles of marine origin contained $\mathrm{NaNO}_{3}$ (no genuine sea salt particle was encountered). Some silicate particles with minor amounts of calcium were observed to be mixed with nitrate, sulfate, and water. Among 24 silicate particles, 10 particles
\end{abstract}

are mixed with water, the presence of which could facilitate atmospheric heterogeneous reactions of silicate particles including swelling minerals, such as montmorillonite and vermiculite, and nonswelling ones, such as feldspar and quartz. This paper provides detailed information on the physicochemical characteristics of these aged individual Asia dust particles through the combined use of the two single-particle analytical techniques, and using this analytical methodology it is clearly shown that internal mixing states of the aged particles are highly complicated.

\section{Introduction}

Nearly every spring, "Asian dust" originating mostly in western or central China's and Mongolia's arid areas is transported to eastern China, the industrialized regions of China, and over the Yellow Sea to Korea, Japan, and even the Pacific Ocean (Uno et al., 2011; Cottle et al., 2012; Wang et al., 2013). Asian dust storms inject immense quantities of dust particles from arid and semiarid areas into the atmosphere and periodically contribute to the large global aerosol load. These particles can affect the radiative balance (Bergstrom et al, 2007) and prevalence of ice nuclei and cloud condensation nuclei (Andreae and Rosenfeld, 2008; Manktelow et al., 2010), as well as the atmospheric deposition of nutrients and toxins (Baker et al., 2003; Paytan et al., 2009). Mineral dust can provide reactive surfaces for heterogeneous reactions with trace atmospheric gases, leading to chemical modification of the particles that ultimately affects the atmospheric chemical balance and photochemical cycle (Price et al., 2004; Sullivan et al., 2007a). At the same 
time, modification of the physicochemical properties of particles can alter their optical properties as well as their direct and indirect radiative forcing (Li-Jones et al., 1998; Xu et al., 2004). Therefore, the atmospheric aging process of Asian dust particles during long-range transport has attracted increasing attention (Huebert et al., 2003; Arimoto et al., 2004; Maxwell-Meier et al., 2004; McNaughton et al., 2004; Formenti et al., 2011; Nie et al., 2012).

The characterization of aged Asian dust particles is important in that (a) it is helpful to understand their impacts on the prevalence of ice nuclei and cloud condensation nuclei because the dust particles coated with soluble materials might reduce their original ice-nucleating ability, enhance their cloud-nucleating ability, and modify their lightscattering and -absorption ability (Tobo et al., 2010; Manktelow et al., 2010); (b) it is helpful to estimate the atmospheric deposition of nutrients on the sea when the air masses carrying dust particles passed over it, as the dust particles containing certain soluble materials (e.g. iron, nitrate, and phosphate) could stimulate phytoplankton growth in the open ocean (Takahashi et al., 2011; Zhu et al., 2013); (c) it is helpful to understand the potential impacts of Asian dust events on human health, such as an increase in daily hospital admissions and clinic visits for a diverse array of allergy-related conditions and for chronic respiratory problems, as certain specific components and size fractions of aged Asian dust particles (rather than the mass of the particles alone) play a significant role in generating specific health effects (Onishi et al., 2012; Watanabe et al., 2011); and (d) it is helpful to assess the impacts of Asian dust particles on urban air quality and address the heterogeneous reactions between air pollutants and mineral dust (Nie, et al., 2012; Wang, et al., 2013).

In our previous studies (Ro et al., 2005; Hwang and Ro, 2005; Hwang et al., 2008; Geng et al., 2009), Asian dust particle samples collected in Korea during 10 dust storm events between 2000 and 2006 were examined using a quantitative energy-dispersive electron probe $\mathrm{X}$-ray microanalysis (EDEPMA), named low- $Z$ particle EPMA. These studies have shown that Asian dust particles experience chemical modification (aging) when they pass through industrialized regions of China and over the Yellow Sea (Ro et al., 2005; Hwang and Ro, 2005; Hwang et al., 2008). For all the Asian dust particle samples investigated, one sample collected on 11 November 2002 was quite interesting, where Ca-containing particles were very abundant (Hwang and Ro, 2005; Ro et al., 2005). This unique sample was examined again and it was demonstrated that the particles in this sample had been extensively aged during long-range transport (Hwang and Ro, 2006). Among the 178 particles analyzed in that work, the number of reacted (aged) particles was 81, and heterogeneous chemical reactions occurred mostly on $\mathrm{CaCO}_{3}$ mineral dust (54 particles) and sea salts ( 26 particles).

Low- $Z$ particle EPMA is a powerful single-particle analytical technique for the characterization of airborne aerosol particles, since the particle size distribution and quantitative chemical composition of individual particles can be obtained without a complicated sample pretreatment process. Moreover, many environmentally important atmospheric particles, e.g. sulfates, nitrates, ammonium, and carbonaceous species, have been elucidated at least semiquantitatively by the application of this technique (Geng et al., 2009). Nevertheless, low- $Z$ particle EPMA has a limitation on molecular speciation, particularly for the organic moiety and silicate particles, because their chemical compositions and crystal structures are so diverse that the elemental concentrations obtained from the X-ray spectra are not sufficient for their speciation. In many cases, airborne particles are internal mixtures of two or more chemical species, for which X-ray analysis is even more difficult. Recently, our group reported that various types of individual airborne particles could be identified clearly by the combined use of low- $Z$ particle EPMA and attenuated total reflectance Fourier transform infrared spectroscopy (ATR-FTIR) imaging, where both the elemental chemical composition and molecular species of the same individual particles can be obtained from their X-ray and ATR-FTIR spectral data (Jung et al., 2010; Song et al., 2010; Malek et al., 2011). Low- $Z$ particle EPMA and ATR-FTIR imaging can provide complementary information on their morphology and elemental concentrations, as well as their molecular species, functional groups, crystal structure, and physical phase of the same individual particles, respectively. The combined use of these two techniques resulted in a better understanding of the physicochemical characteristics of individual mineral, aged sea salt, and secondary aerosol particles than when the techniques were used alone (Jung et al., 2010; Song et al., 2010). In this study, an Asian dust sample collected on 11 November 2002 was examined again to obtain detailed physicochemical characteristics of the aged Asian dust particles, which experienced extensive chemical modification during long-range transport, by the combined application of low- $Z$ particle EPMA and ATR-FTIR imaging. The application of this new analytical methodology to the characterization of the aged Asian dust particles clearly showed that their internal mixing states are highly complicated.

\section{Experimental section}

\subsection{Sample}

On 11 November 2002 when an Asian dust storm event occurred, aerosol particle samples were collected on the roof of a campus building of Hallym University located in ChunCheon, Korea. ChunCheon $\left(37^{\circ} 89^{\prime} \mathrm{N}, 127^{\circ} 73^{\prime} \mathrm{E}\right)$ is a relatively small city (population: 0.26 million; area: $1116 \mathrm{~km}^{2}$ ) with a mostly rural character outside of the central district that is free of industrial complexes. This event was a recordbreaking episode and was reported to originate from the Gobi and Inner Mongolian deserts (Chung et al., 2003). The 
single-particle analytical results for the samples using low- $Z$ particle EPMA and more details on the samples can be found elsewhere (Hwang and Ro, 2005, 2006). Particles were sampled on $\mathrm{Ag}$ foil using a seven-stage May cascade impactor. The May impactor has, at a $20 \mathrm{~L} \mathrm{~min}^{-1}$ sampling flow, an aerodynamic cut-off of $16,8,4,2,1,0.5$, and $0.25 \mu \mathrm{m}$ for stages \#1-7, respectively. The samples were placed in plastic carriers, sealed, and stored in a desiccator. Overall, 109 particles for the stage 3 sample were analyzed in this study.

\subsection{Low- $Z$ particle EPMA}

Low- $Z$ particle EPMA was applied to obtain morphological and elemental compositional information on the individual particles before the ATR-FTIR imaging measurements, as the morphological modification of particles occurred when the IRE crystal made contact with the sample for ATRFTIR imaging measurements. Low- $Z$ particle EPMA measurements were carried out using a Jeol JSM-6390 scanning electron microscope (SEM) equipped with an Oxford Link SATW ultrathin window EDX detector. The resolution of the detector is $133 \mathrm{eV}$ for $\mathrm{Mn}-\mathrm{K} \alpha \mathrm{X}$-rays. The $\mathrm{X}$-ray spectra were recorded using Oxford INCA Energy software. An accelerating voltage of $10 \mathrm{kV}$ was chosen to achieve the optimal experimental conditions, such as a low background level in the spectra and high sensitivity for low- $Z$ element analysis. The beam current was $1.0 \mathrm{nA}$ for all measurements. A more detailed discussion of the measurement conditions is reported elsewhere (Ro et al., 1999). The net X-ray intensities of the elements were obtained by a nonlinear leastsquares fitting of the collected spectra, using the AXIL program (Vekemans et al., 1994). The elemental concentrations of the individual particles were determined from their X-ray intensities by the application of a Monte Carlo simulation combined with reverse successive approximations (Ro et al., 2004). The quantification procedure provided results accurate to within $12 \%$ of the relative deviations between the calculated and nominal elemental concentrations when the method was applied to various types of standard particles, such as $\mathrm{NaCl}, \mathrm{Al}_{2} \mathrm{O}_{3}, \mathrm{CaSO}_{4} \cdot 2 \mathrm{H}_{2} \mathrm{O}, \mathrm{Fe}_{2} \mathrm{O}_{3}, \mathrm{CaCO}_{3}$, and $\mathrm{KNO}_{3}$ (Ro et al., 2004). The low- $Z$ particle EPMA method can provide quantitative information on the chemical composition of individual particles, and particles can be classified based on their chemical species.

\subsection{ATR-FTIR imaging technique}

ATR-FTIR imaging measurements were performed using a Perkin Elmer Spectrum 100 FTIR spectrometer interfaced to a Spectrum Spotlight 400 FTIR microscope. For ATR imaging, an ATR accessory employing a germanium hemispherical internal reflection element (IRE) crystal with a diameter of $600 \mu \mathrm{m}$ was used. The ATR accessory was mounted on the XY stage of the FTIR microscope, and the IRE crystal made contact with the sample via a force lever. The ultimate (lat- eral) spatial resolution of the IR imaging is approximately equal to the wavelength of the incident IR radiation. In addition, the hemispherical IRE crystal acts like a lens in that the IR beam is condensed when the beam strikes the IRE. The extent of condensation is proportional to the refractive index of the IRE material (4.0 for germanium) (Griffiths and de Haseth, 2007). Therefore, a spatial resolution of $3.1 \mu \mathrm{m}$ at $1726 \mathrm{~cm}^{-1}(5.79 \mu \mathrm{m})$ was achieved beyond the ultimate spatial resolution limit. A $16 \times 1$ pixel mercury cadmium telluride (MCT) array detector was used to obtain FTIR images with a pixel size of $1.56 \mu \mathrm{m}$. For each pixel, an ATR-FTIR spectrum, ranging from 680 to $4000 \mathrm{~cm}^{-1}$ with a spectral resolution of $8 \mathrm{~cm}^{-1}$, was obtained from eight interferograms, which were co-added and Fourier transformed. The position of the crystal on the sample was determined using an optical microscope equipped with a light-emitting diode and chargecoupled device camera. The optical image was used to identify the same single particles that were analyzed using low- $Z$ particle EPMA before ATR-FTIR imaging because optical microscopy provides an image of sufficient spatial resolution to help easily locate the same image field observed by low- $Z$ particle EPMA. Spectral data processing was performed using Perkin Elmer Spectrum IMAGE software, where the images were corrected for atmospheric effects and the spectral information at each pixel was extracted by principal component analysis (PCA). A more detailed description of ATRFTIR imaging can be found elsewhere (Jung et al., 2010; Song et al., 2010; Malek et al., 2011).

\section{Results and discussion}

Figure 1 shows the secondary electron image (SEI) obtained before the ATR-FTIR imaging measurements (Fig. 1a), the visible light optical image (Fig. 1b), the ATR-FTIR image (Fig. 1c), and the SEI after ATR-FTIR imaging (Fig. 1d) of the same 109 individual airborne Asian dust particles on $\mathrm{Ag}$ foil. For the combined application of the two single-particle analytical techniques, the morphology and chemical compositions of all the particles in the image field were obtained. Optical microcopy was used to locate the same image field for ATR-FTIR imaging (Fig. 1b). After the relocation of the image field, the sample was placed in contact with the IRE crystal for the ATR-FTIR imaging measurement. The ATRFTIR image (Fig. 1c) was obtained by PCA analysis after the first differentiation of the original ATR-FTIR spectra at all of the pixels in the image. Although the qualities of the SEI and ATR-FTIR image differ due to the inherently different spatial resolutions of the images, the same patterns of particle location among the images ensured that the same micrometer-sized particles were observed. Their equivalent diameters ranged from 1.5 to $14.0 \mu \mathrm{m}$ (before the ATR-FTIR imaging), determined by measuring the projected area of the particle in the SEI and calculating the diameter of a circle with equal area to the projected area. The area of each image 


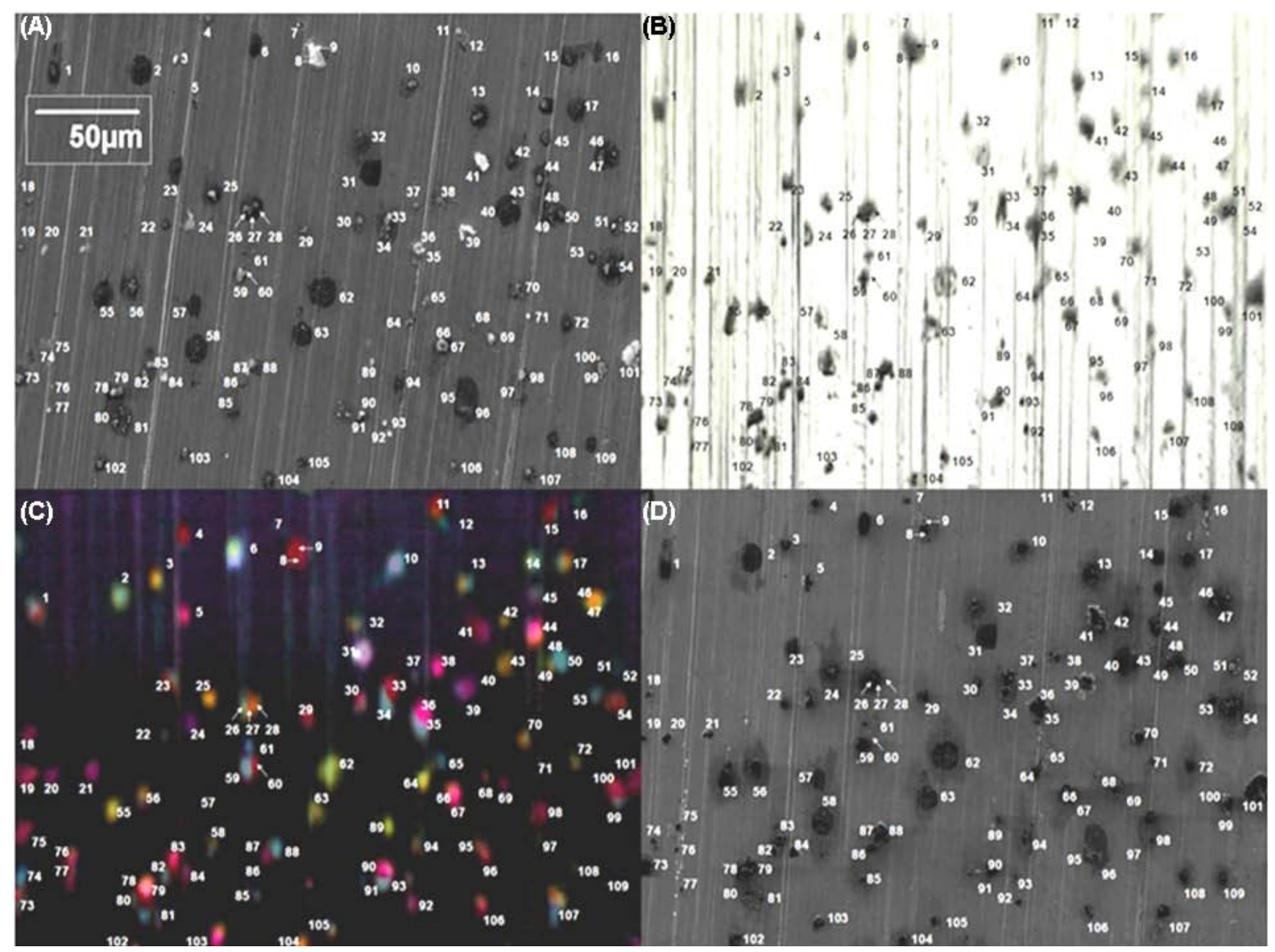

Fig. 1. (A) Secondary electron image (SEI) before the ATR-FTIR imaging measurements, (B) visible light optical image, (C) ATR-FTIR image, and (D) SEI after the ATR-FTIR imaging of the same 109 individual airborne particles on Ag foil.

was approximately $300 \times 200 \mu \mathrm{m}^{2}$. The number of pixels for the ATR-FTIR image is $\sim 25000$ considering that the pixel size of the ATR-FTIR image is $1.56 \times 1.56 \mu \mathrm{m}^{2}$. All pixels in the image contained the full IR spectra ranging from 680 to $4000 \mathrm{~cm}^{-1}$. Although the experimental ATR-FTIR imaging data were obtained on a $1.56 \times 1.56 \mu \mathrm{m}^{2}$ pixel size, the manufacture's software interpolates the ATR-FTIR imaging pixel data onto a display image, so that the display image appears better than the instrument resolution.

The SEIs (Fig. 1a and d) clearly show the morphology and locations of the 109 particles before and after the ATR-FTIR imaging. For ATR-FTIR imaging, the sample was placed in contact with the IRE crystal so that some force was applied to the sample during contact. When good contact was made and the sample was well pressed against the IRE crystal, the particles were (partly or fully) embedded into the ductile $\mathrm{Ag}$ collecting foil. For example, some nonconducting mineral particles sitting on the $\mathrm{Ag}$ foil (e.g. particles \#3, 8, 9, 35,
$36,39,41$, and 101) appeared bright because of the high secondary and backscattered electron (SE and BSE) yields of insulating particles (Fig. 1a), whereas the particles in the SEI taken after the FTIR measurements appeared dark as electrons can flow from the embedded particles to the metallic foil, resulting in low SE and BSE yields (Fig. 1d) (Goldstein et al., 2003). Most particles in Fig. 1a appeared dark due to their lower BSE yield than that of the Ag foil, resulting from their lower average atomic number (Goldstein et al., 2003). Many particles (\#13, 25, 32, and 62, to name a few) in Fig. 1d showed a faint, blurred shade, which is different from the original dark particles in Fig. 1a, after the force by the IRE crystal was applied to the particles during contact, suggesting that the dark particles in Fig. 1a contain water. A previous study showed that those dark particles were collected as water droplets (Hwang and Ro, 2006).

Based on the morphological, X-ray spectral, and ATRFTIR spectral data, 109 individual particles were classified 


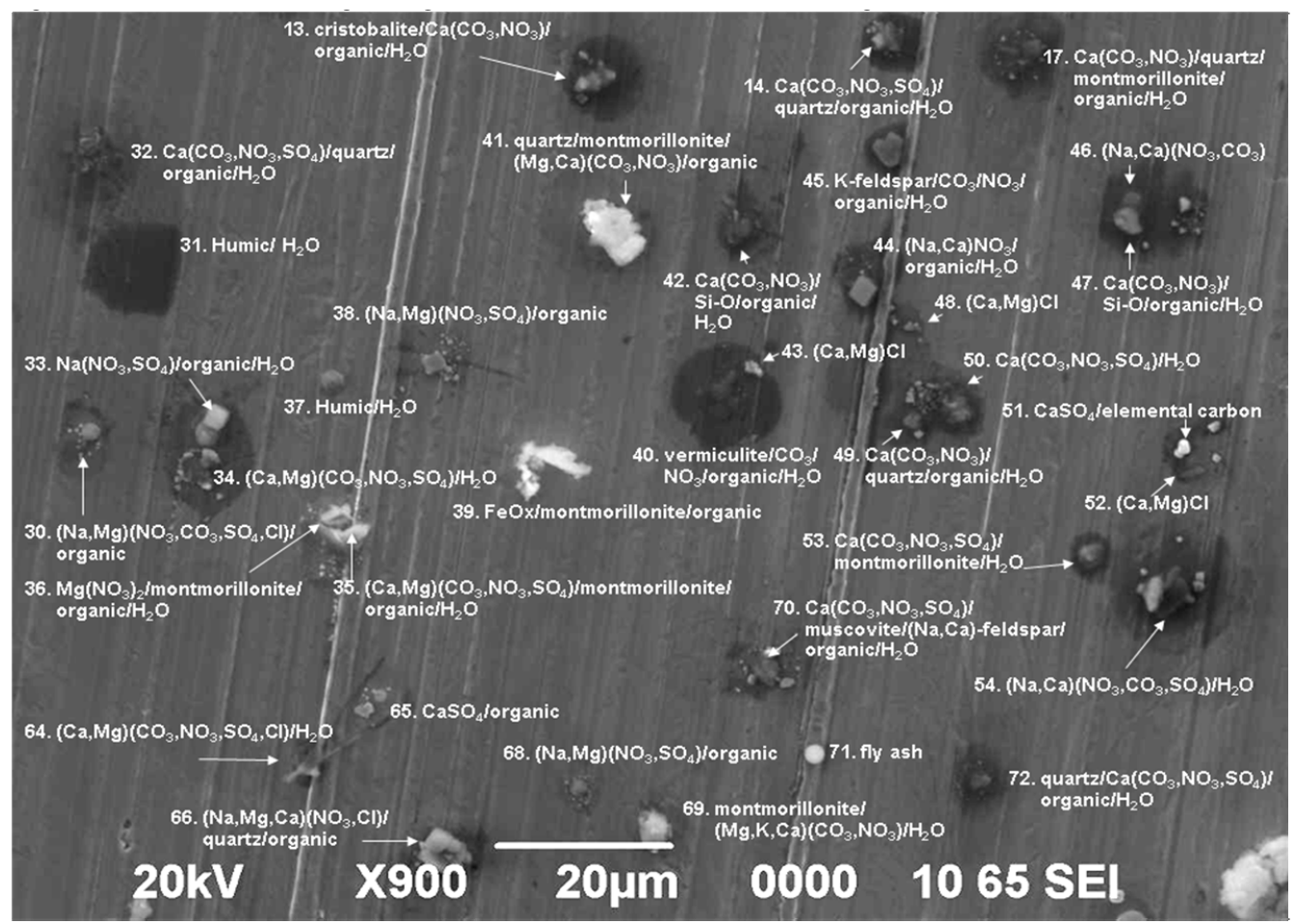

Fig. 2. An SEI obtained in a higher magnification than the overall SEI shown in Fig. 1.

into different particle types, such as Ca-containing, $\mathrm{NaNO}_{3}$ containing, silicates, and miscellaneous particles. Table S1 in the Supplement shows the chemical speciation results for all 109 particles determined by the combined use of the two techniques. The third and fourth columns of Table S1 list the elemental concentration and chemical species of each particle obtained from the low- $Z$ particle EPMA data, respectively. Details pertaining to the low- $Z$ particle EPMA data treatment and interpretation can be found in previous papers (Geng et al., 2009, 2010). The following gives a brief summary of how the particles were classified. Low $Z$ particle EPMA can provide quantitative information on the chemical composition. First, the particles were regarded to be composed of only one chemical species when the chemical species constituted at least a $90 \%$ atomic fraction. Second, efforts were made to specify the chemical species, even for particles mixed internally with two or more chemical species. The mixed particles were specified based on all of chemical species with $>10 \%$ in the formula fraction. Third, ED-EPMA has high detection limits of $0.1-1.0 \%$ in weight mainly due to its high bremsstrahlung background level. Therefore, elements with an atomic concentration less than $1.0 \%$ were not included in the chemical speciation procedure.

The ATR-FTIR absorption peaks and chemical species obtained from the ATR-FTIR spectral data are listed in the fifth and sixth columns of Table S1, respectively. The ATR-FTIR spectral data was used qualitatively for molecular speciation and/or functional group analysis because of the difficulty in assessing molecular species of individual particles quantitatively using ATR-FTIR spectral data when they are internal mixtures. An in-house ATR-FTIR spectral library was initially consulted to specify the molecular species of individual particles using the ATR-FTIR spectral data; inorganic compounds and minerals commonly encountered in airborne particle samples were measured by ATR-FTIR to generate a custom ATR-FTIR library (Jung et al., 2010; Malek et al., 2011). When the ATR-FTIR spectrum of an individual particle was too complex to clearly specify all the chemical species of the particle, the IR absorption peaks were examined by functional group analysis based on IR peak data available in the literature (Niemeyer et al., 1992; Allen et al., 1994; Cabaniss et al., 1998; Specht and Frimmel, 2001; Max and Chapados, 2004; Hay and Myneni, 2007; Coury and Dillner, 2008). The seventh column of Table S1 lists the chemical species identified by the combined use of the two single-particle analytical techniques, which are the particle types used for the discussion. Particle types and chemical species of all 109 particles determined by the combined use of low- $Z$ particle EPMA and ATR-FTIR imaging are also summarized in Table 1.

Figure 2 shows an SEI obtained at higher magnification $(\times 900)$ than an overall SEI (Fig. 1a with $\times 400)$, where a more detailed morphology of the particles is shown together with their particle types. For the other particles, Figs. S1$\mathrm{S} 4$ in the Supplement provide their SEIs obtained at higher magnification as well as their particle types. For the notation 
Table 1. Particle types and chemical species of all 109 particles determined by the combined use of low-Z particle EPMA and ATR-FTIR imaging.

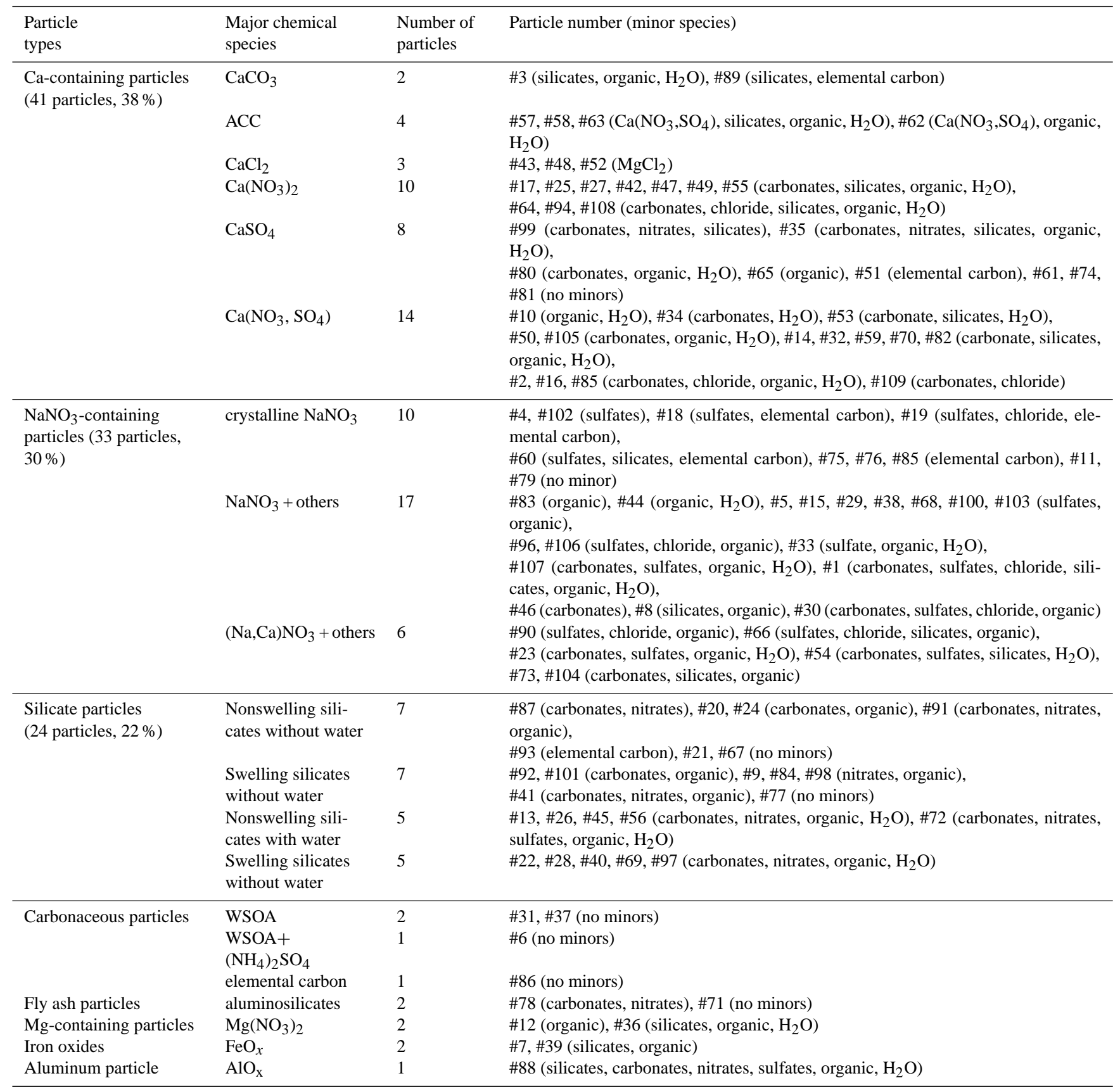

of particle types, a unique notation system was devised. A particle notated as $(\mathrm{Mg}, \mathrm{Ca})\left(\mathrm{NO}_{3}, \mathrm{SO}_{4}\right)$ is an internal mixture of $\mathrm{Mg}\left(\mathrm{NO}_{3}\right)_{2}, \mathrm{MgSO}_{4}, \mathrm{Ca}\left(\mathrm{NO}_{3}\right)_{2}$, and $\mathrm{CaSO}_{4}$ species. A particle denoted cristobalite $/ \mathrm{Ca}\left(\mathrm{CO}_{3}, \mathrm{NO}_{3}\right) /$ organic $/ \mathrm{H}_{2} \mathrm{O}$ indicates that the particle is a mixture of cristobalite, $\mathrm{CaCO}_{3}$, $\mathrm{Ca}\left(\mathrm{NO}_{3}\right)_{2}$, and organic species, with the most abundant chemical species listed first. If water is present in the particle, it is placed last just to indicate its presence. Among 109 particles, Ca-containing particles (41 particles; $38 \%$ ) were the most abundant, followed by $\mathrm{NaNO}_{3}$-containing (33 particles, $30 \%$ ), silicate ( 24 particles, $22 \%$ ), and miscellaneous particles (11 particles, $10 \%$ ) (see Table 1).

\subsection{Ca-containing particles}

Among the 109 particles, the number of $\mathrm{Ca}$-containing particles was 41 , where just two particles are $\mathrm{CaCO}_{3}$ and the others are aged (reacted) ones containing $\mathrm{Ca}\left(\mathrm{NO}_{3}\right)_{2}, \mathrm{CaSO}_{4}$, 


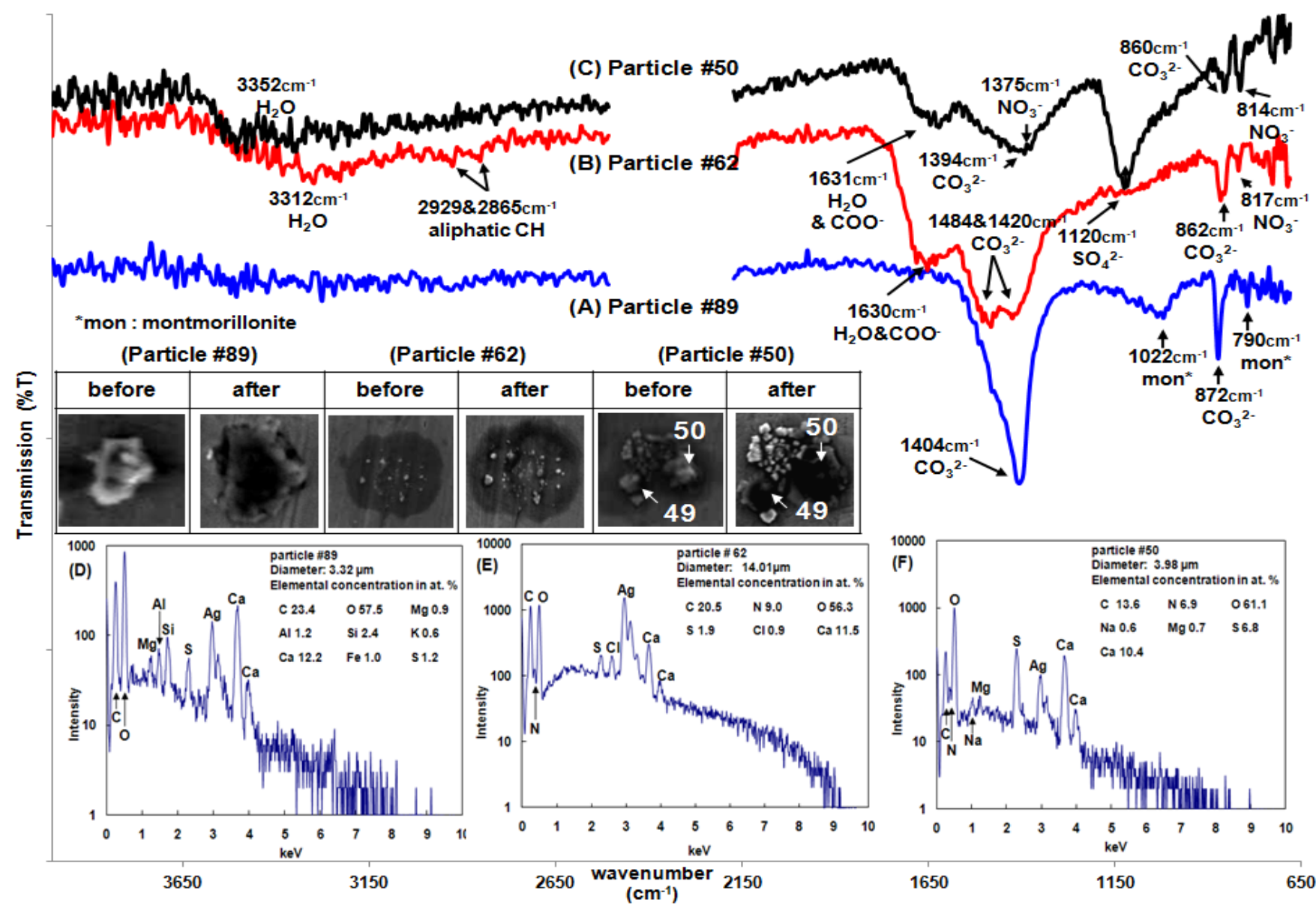

Fig. 3. ATR-FTIR and X-ray spectra of typical Ca-containing particles and SEIs of particles obtained before and after the ATR-FTIR imaging. The data for the $2200-2530 \mathrm{~cm}^{-1}$ region where atmospheric $\mathrm{CO}_{2}$ peaks are present were deleted for clarity.

or both, which are the reaction products of $\mathrm{CaCO}_{3}$ particles with $\mathrm{NO}_{\mathrm{x}} / \mathrm{HNO}_{3}$ and/or $\mathrm{SO}_{\mathrm{x}}$. Almost all Ca-containing particles (see particles \#14, 17, 32, 42, 47, 49, 50, and 53 in Fig. 2) were collected as water droplets because they appear dark in their SEIs (Hwang and Ro, 2006). In addition, the presence of IR peaks of $\mathrm{H}_{2} \mathrm{O}$ at $1620-1630$ and $3300-3440 \mathrm{~cm}^{-1}$ in their ATR-FTIR spectra clearly shows that the dark particles contain water. (The assignment of IR peaks mentioned in this work are listed in Table S2 of the Supplement to aid the reader in understanding the discussion of the speciation by ATR-FTIR below.)

\subsubsection{Calcite particles}

Figure 3 presents the ATR-FTIR and X-ray spectral data and SEIs of the three typical Ca-containing particles. The ATR-FTIR spectrum, X-ray spectrum and elemental atomic concentrations, and SEIs (taken before and after ATR-FTIR imaging) of particle \#89 are presented in Fig. 3a and d and the insets, respectively. Based on low- $Z$ particle EPMA, its major elements were $\mathrm{O}$ (58\% in atomic fraction), $\mathrm{C}$ (23\%),
$\mathrm{Ca}(12 \%), \mathrm{Si}(2 \%), \mathrm{Al}(1 \%), \mathrm{S}(1 \%), \mathrm{Mg}(1 \%)$, and $\mathrm{Fe}$ $(1 \%)$, suggesting that particle $\# 89$ is a mixture of $\mathrm{CaCO}_{3}$ and carbonaceous species with minor content of aluminosilicate and sulfate. Its bright and angular SEI obtained before ATR-FTIR imaging indicates its soil origin. The presence of the $\mathrm{CaCO}_{3}$ moiety in particle \#89 was confirmed by the strong IR peaks from $\mathrm{CO}_{3}^{2-}$ of calcite at 872 and $1404 \mathrm{~cm}^{-1}$ in its ATR-FTIR spectrum, and its ATR-FTIR spectral data clearly show that the aluminosilicate moiety is montmorillonite due to its IR peaks at 790 and 1022 (Jung et al., 2010). Because the elemental concentrations of $\mathrm{C}$ and $\mathrm{Ca}$ are $23 \%$ and $12 \%$, respectively, where $12 \% \mathrm{C}$ is combined with $\mathrm{Ca}$, the remaining $\sim 11 \%$ carbon species appear to be IR-inactive elemental carbon because no organic IR peak was observed. No IR peak for sulfate at $1120 \mathrm{~cm}^{-1}$ was observed, even though the atomic concentration of sulfur by EPMA is significant $(\sim 1 \%)$, suggesting that sulfate appears to be concentrated locally at the region where the X-rays were collected. The ATR-FTIR spectrum provides information on the chemical species and functional groups of the particle, but a quantitative assessment of those species is still needed. The 
combined use of X-ray and ATR-FTIR showed that particle \#89 was a mixture of calcite, elemental carbon, and montmorillonite, and the majority of the particle was calcite. Only two calcite-rich particles did not experience aging during long-range transport, namely particles \#3 and 89.

\subsubsection{Amorphous calcium carbonate (ACC) particles}

The ATR-FTIR spectrum, X-ray spectrum and elemental atomic concentrations, and SEIs of particle \#62 are presented in Fig. $3 b$ and e and the insets, respectively. Low- $Z$ particle EPMA revealed the major elements to be O $(56 \%)$, $\mathrm{C}$ (21\%), Ca (12\%), N (9\%), S (2\%), and $\mathrm{Cl}(1 \%)$, suggesting that particle \#62 is a mixture of $\mathrm{CaCO}_{3}$, nitrate, and carbonaceous species with minor sulfate and chloride. Its dark and circular SEI indicates that it was collected as a water droplet. Indeed, the weak and broad IR absorption peak at $\sim 3312 \mathrm{~cm}^{-1}$ was assigned to the water moiety. Naturally occurring $\mathrm{CaCO}_{3}$ can exist in six different forms, i.e. calcite, aragonite, vaterite, monohydrocalcite, and calcium carbonate hexahydrate, which are crystalline $\mathrm{CaCO}_{3}$ of a soil origin, and amorphous calcium carbonate (ACC) of a possible biogenic origin (Beniash et al., 1997; Addadi et al., 2003; Weiner et al., 2003). The six different $\mathrm{CaCO}_{3}$ forms were reported to have different IR spectra. In particular, ACC can be distinguished clearly from the crystalline $\mathrm{CaCO}_{3}$ forms because ACC shows two split peaks of the asymmetric stretching vibration due to the deficient symmetric environment of the $\mathrm{CO}_{3}^{2-}$ ion (Addadi et al., 2003; Weiner et al., 2003). In Fig. 3b, particle \#62 clearly shows two $\mathrm{CO}_{3}^{2-}$ peaks at 1420 and $1484 \mathrm{~cm}^{-1}$, which are characteristic for ACC. Until now it has been reported that ACC can only be emitted from the skeletal components of various sea creatures to the air (Addadi et al., 2003; Weiner et al., 2003). Therefore, these ACC particles might have been entrained when Asian dust particles passed over the Yellow Sea. However, biogenic ACC in the skeletal components is not observed frequently in the atmospheric environment or elsewhere in nature. Among the 41 Ca-containing particles, four were ACC-rich particles, namely particles $\# 57,58,62$, and 63 , which is too many for the ACC-rich particles to be of biogenic origin. In addition, small and bright crystals inside dark particle \#62 (see insets in Fig. 3) mainly contain $\mathrm{Ca}, \mathrm{C}$, and O elements in their X-ray spectra (not shown), indicating that the small bright crystals are $\mathrm{CaCO}_{3}$. The other three ACC particles except for particle \#62 contained a small amount of silicate species (see Table S1 of the Supplement), strongly suggesting their soil origin. Some carbonaceous species were organic because the IR peaks of the aliphatic $\mathrm{CH}$ group are present at 2865 and $2929 \mathrm{~cm}^{-1}$. In addition, the IR peak at $1630 \mathrm{~cm}^{-1}$ was assigned to carboxylic ions $\left(\mathrm{COO}^{-}\right)$(Hay and Myneni, 2007), most likely from humic substances (Niemeyer et al., 1992) and/or organic compounds, such as oxygenated carboxylic carbonyl compounds (Russell et al., 2002). The IR peak at $1630-1640 \mathrm{~cm}^{-1}$ can be from a water moiety, but water has also a stronger and broader peak at $3200-3400 \mathrm{~cm}^{-1}$ than at $1630-1640 \mathrm{~cm}^{-1}$. Because the peak at $\sim 1630 \mathrm{~cm}^{-1}$ was stronger than that at $\sim 3312 \mathrm{~cm}^{-1}$, it must be convoluted with the IR peak from carboxylic ions. The IR peak of nitrate at $\sim 1350 \mathrm{~cm}^{-1}$ was not observed because the carbonate peaks were too strong. The small peaks at 817 and $1120 \mathrm{~cm}^{-1}$, respectively, indicate that $\mathrm{N}$ and $\mathrm{S}$ elements detected by EPMA are in the forms of nitrate and sulfate, respectively. Although $\mathrm{Cl}$ was detected by EPMA, there was no IR peak related to this chloride species, most likely because it exists as IRinactive $\mathrm{CaCl}_{2}$. Through the combined use of X-ray and ATR-FTIR spectral data, particle \#62 was found to be a mixture of ACC, organic, nitrate, sulfate, and water, and the majority of the particle was ACC. The chemical modification of calcite into nitrates and sulfates during the long-range transport of Asian dust particles has been reported extensively (Arimoto et al., 2004; Ro et al., 2005; Hwang and Ro, 2005, 2006; Sullivan et al., 2007a; Shi et al., 2008; Hwang et al., 2008; Geng et al., 2009). However, this is the first report of airborne ACC particles observed in Asian dust particle samples to the best of the authors' knowledge. Crystalline calcite particles cannot absorb water, but the observed ACC particles can be hygroscopic because they were collected as water droplets so that their radiative forcing and reactivity should be different from crystalline $\mathrm{CaCO}_{3}$ particles. In a laboratory experiment, it was also mentioned that hygroscopic behavior of ACC would be dramatically different from that of calcite (Sullivan et al., 2010).

\subsection{3 $\mathrm{CaCl}_{2}$-containing particles}

Three particles, namely particles \#43, 48, and 52 (see their morphology in Fig. 2 and their elemental compositions in Table $\mathrm{S} 1$ of the Supplement), were $\mathrm{CaCl}_{2}$-containing ones. Their X-ray spectral data clearly show that $\mathrm{CaCl}_{2}$ is the major species with minor $\mathrm{Mg}, \mathrm{Al}$, and/or $\mathrm{Si}$, and no IR peaks were observed because $\mathrm{CaCl}_{2}$ and $\mathrm{MgCl}_{2}$ are IR inactive. A few studies reported the chemical modification of $\mathrm{CaCO}_{3}$ mineral particles to $\mathrm{CaCl}_{2}$, particularly in the marine boundary layer, where the $\mathrm{HCl}$ level is sufficiently high for their conversion (Sullivan et al., 2007b; Tobo et al., 2010). Although the Asian dust sample was collected in ChunCheon, which is $\sim 110 \mathrm{~km}$ away from the coast, the $\mathrm{CaCl}_{2}$ particles must have been formed when the Asian dust particles passed over the Yellow Sea. This is the first report of the inland field observation of $\mathrm{CaCl}_{2}$ particles probably converted from $\mathrm{CaCO}_{3}$.

\subsubsection{Calcium nitrate and sulfate}

Among the $41 \mathrm{Ca}$-containing particles, 32 particles experienced chemical modification through heterogeneous reactions of $\mathrm{CaCO}_{3}$ particles with $\mathrm{SO}_{\mathrm{x}} / \mathrm{H}_{2} \mathrm{SO}_{4}$ and/or $\mathrm{NO}_{\mathrm{x}} / \mathrm{HNO}_{3}$ during long-range transport (Table 1). As a typical example of such particles, the ATR-FTIR spectrum, 
$\mathrm{X}$-ray spectrum and elemental atomic concentrations, and SEIs of particle \#50 are presented in Fig. $3 \mathrm{c}$ and $\mathrm{f}$ and the insets, respectively. Its major elements were $\mathrm{O}(61 \%), \mathrm{C}$ $(14 \%), \mathrm{Ca}(10 \%), \mathrm{N}(7 \%)$, and $\mathrm{S}(7 \%)$, suggesting that particle \#50 was a mixture of $\mathrm{CaCO}_{3}, \mathrm{Ca}\left(\mathrm{NO}_{3}\right)_{2}, \mathrm{CaSO}_{4}$, and carbonaceous species. Its dark and circular SEI indicates that it was collected as a water droplet, which is supported by the presence of IR absorption peaks at 1631 and $\sim 3352 \mathrm{~cm}^{-1}$ from the water moiety. Some bright particles inside the dark region (see SEIs in insets of Fig. 3) would be crystalline $\mathrm{CaCO}_{3}$. The presence of a strong IR peak at $1120 \mathrm{~cm}^{-1}$ and sharp peaks at 814 and $860 \mathrm{~cm}^{-1}$ confirmed the presence of $\mathrm{SO}_{4}^{2-}, \mathrm{NO}_{3}^{2-}$, and $\mathrm{CO}_{3}^{-}$moieties, respectively. The IR peaks characteristic for $\mathrm{NO}_{3}^{2-}$ and $\mathrm{CO}_{3}^{-}$ions at 1375 and $1394 \mathrm{~cm}^{-1}$, respectively, were convoluted to a broad and asymmetric IR peak at $\sim 1390 \mathrm{~cm}^{-1}$. Some nitrate and sulfate most likely existed in acidic forms because the sum of the $\mathrm{C}, \mathrm{N}$, and $\mathrm{S}$ contents (24\%) was larger than that of $\mathrm{Ca}(10 \%)$. Organic species should be present due to the characteristic IR peak of carboxylic ions at $1631 \mathrm{~cm}^{-1}$ (Hay and Myneni, 2007). Through the combined use of X-ray and ATR-FTIR spectral data, particle \#50 was found to be a mixture of $\mathrm{CaCO}_{3}, \mathrm{Ca}\left(\mathrm{NO}_{3}\right)_{2}, \mathrm{CaSO}_{4}$, organics, and water, and the major components of the particle were nitrates and sulfates including their acidic species. Among the 39 aged (reacted) Ca-containing particles, the number of particles containing nitrate, sulfate, and both were 10,8 , and 14 , respectively (Table 1).

\section{2 $\mathrm{NaNO}_{3}$-containing particles}

Among the 109 particles examined, 33 were $\mathrm{NaNO}_{3}$ containing particles, which are the reaction products between sea salt particles and $\mathrm{NO}_{\mathrm{x}} / \mathrm{HNO}_{3}$ (Laskin et al., 2002), without observation of genuine sea salt particles (Table 1). The lack of genuine sea salt particles indicates the facile formation of $\mathrm{NaNO}_{3}$ species through the heterogeneous reactions of sea salts.

\subsubsection{Crystalline $\mathrm{NaNO}_{3}$ particles}

Among the $33 \mathrm{NaNO}_{3}$-containing particles, 10 were crystalline. As a typical example, the ATR-FTIR spectrum, Xray spectrum and elemental atomic concentrations, and SEIs of particle \#79 are presented in Fig. 4a and d and the insets, respectively. The major elements were $\mathrm{O}(54 \%), \mathrm{Na}$ $(24 \%), \mathrm{N}(22 \%)$, and $\mathrm{Ca}(1 \%)$, suggesting that particle \#79 is a $\mathrm{NaNO}_{3}$ particle. Its bright and cubic SEI indicates that it is a crystalline solid, which is supported by the absence of IR peaks of water. In addition, a sharp IR peak at $1786 \mathrm{~cm}^{-1}$ is characteristic of crystalline $\mathrm{NaNO}_{3}$ species (Song et al., 2010). The ATR-FTIR spectral data clearly supports that this is a $\mathrm{NaNO}_{3}$ particle because the IR peaks at 833,1064 , and $1352 \mathrm{~cm}^{-1}$ are characteristic of $\mathrm{NO}_{3}^{-}$ions. On the other hand, ATR-FTIR provides additional information on the chemical species of this particle; i.e. nitrite species are also present due to an IR peak at $1254 \mathrm{~cm}^{-1}$ of $\mathrm{NO}_{2}^{-}$ion. Nitrite can be formed through heterogeneous reactions with the involvement of $\mathrm{HONO}, \mathrm{ClNO}_{2}$, and $\mathrm{HNO}_{3}$ (Thornton et al., 2010; Ziemba et al., 2010) or through a photochemical reaction from a concentrated aqueous nitrate solution (Roca et al., 2008). Several studies reported the beam damage of $\mathrm{NaNO}_{3}$ particles under an electron beam, probably resulting in the decomposition of $\mathrm{NaNO}_{3}$ to $\mathrm{NaNO}_{2}$ (Allen et al., 1998; Worobiec et al., 2003; Laskin et al., 2005). A preliminary study of electron beam damage also revealed a $\mathrm{NO}_{2}^{-}$peak in ATR-FTIR spectra when $\mathrm{NaNO}_{3}$ particles generated by nebulization from a $\mathrm{NaNO}_{3}$ aqueous solution were exposed to an electron beam for a substantial amount of time. Therefore, it is unclear if the $\mathrm{NO}_{2}^{-}$ions observed in the $\mathrm{NaNO}_{3}$-containing particles are of atmospheric origin or due to electron beam damage. The combined use of $\mathrm{X}$ ray and ATR-FTIR spectral data showed that particle \#79 was a $\mathrm{NaNO}_{3}$ particle formed by heterogeneous reactions between primary sea salts and $\mathrm{NO}_{\mathrm{X}} / \mathrm{HNO}_{3}$. Among the 10 crystalline $\mathrm{NaNO}_{3}$-containing particles, the X-ray spectral data of 6 particles showed additional carbonaceous species without corresponding IR peaks, indicating that this carbonaceous species is IR-inactive elemental carbon. Many studies have been performed on the hygroscopic behavior of laboratory-generated $\mathrm{NaNO}_{3}$ aerosols, with most of the studies reporting that $\mathrm{NaNO}_{3}$ aerosols showed no distinct deliquescence and efflorescence, i.e. continuous growth and shrinkage during humidifying and dehydration processes, respectively (Gysel et al. 2002; Gibson et al., 2006; Liu et al., 2008; Lu et al., 2008; Hu et al., 2010). These types of $\mathrm{NaNO}_{3}$ aerosols were reported to be amorphous solids at low relative humidity that were round in shape (Hoffman et al., 2004; Liu et al., 2008). In this work, many $\mathrm{NaNO}_{3}$ particles were observed as crystalline solids, indicating that ambient $\mathrm{NaNO}_{3}$ particles show different hygroscopic behavior from that of the laboratory-generated $\mathrm{NaNO}_{3}$ particles, mainly due to their different nucleation mechanisms (Kim et al., 2012). As the ambient $\mathrm{NaNO}_{3}$ particles can have more chance to contain crystal germs such as soot and/or minerals, they can crystallize heterogeneously on these seeds, whereas the laboratory-generated aerosols seem to follow a homogeneous nucleation process.

\subsection{2 $\mathrm{NaNO}_{3}$ particles internally mixed with other chemical species}

Among the $33 \mathrm{NaNO}_{3}$-containing particles, 23 particles were observed to be internally mixed with other chemical species, such as other inorganic species, silicate minerals, and/or carbonaceous species, where 21 particles are mixed with carbonaceous species. As a typical example, ATR-FTIR spectrum, X-ray spectrum and elemental atomic concentrations, and SEIs of particle \#33 are shown in Fig. $4 \mathrm{~b}$ and e and the insets, respectively. Its major elements were O (58\%), 


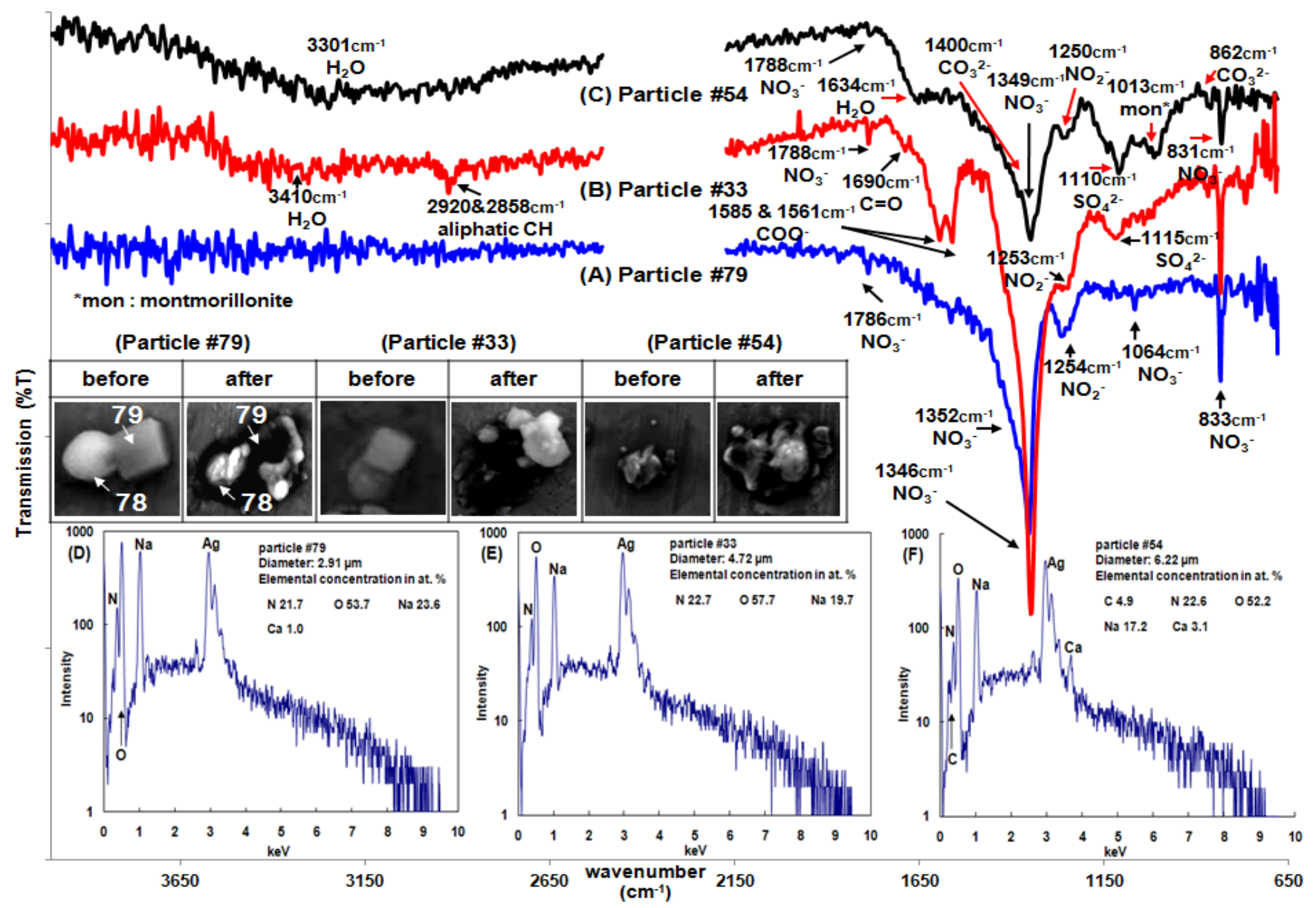

Fig. 4. ATR-FTIR and X-ray spectra of typical NaNO3-containing particles and SEIs of particles obtained before and after ATR-FTIR imaging. The data for the $2200-2530 \mathrm{~cm}^{-1}$ region where atmospheric $\mathrm{CO}_{2}$ peaks are present were deleted for clarity.

$\mathrm{Na}(23 \%)$, and $\mathrm{N}(20 \%)$, suggesting that particle \#33 is a $\mathrm{NaNO}_{3}$ particle. Its bright and cubic SEI indicates that it is a crystalline solid, supported by the presence of an IR peak of crystalline $\mathrm{NaNO}_{3}$ species at $1788 \mathrm{~cm}^{-1}$. However, its ATR-FTIR spectral data are too complex to be just for a crystalline $\mathrm{NaNO}_{3}$-containing particle because of the IR peaks of organic, sulfate, and water moieties in addition to those of nitrate ions. Certainly, the $\mathrm{NaNO}_{3}$ moiety is major due to its strong IR peaks at 833 and $1346 \mathrm{~cm}^{-1}$. Minor $\mathrm{Na}_{2} \mathrm{SO}_{4}$ and water moieties based on the IR peaks at 1115 and $\sim 3410 \mathrm{~cm}^{-1}$, respectively, are also present. The significant content of organic moiety is obvious from the strong IR peaks of $\mathrm{COO}^{-}$at 1561 and $1585 \mathrm{~cm}^{-1}$ and the weak peaks of aliphatic $\mathrm{CH}$ and carbonyl at $\sim 2900 \mathrm{~cm}^{-1}$ (Allen et al., 1994; Coury and Dillner, 2008) and $1690 \mathrm{~cm}^{-1}$ (Niemeyer et al., 1992; Max and Chapados, 2004), respectively. Although only $\mathrm{N}, \mathrm{O}$, and $\mathrm{Na}$ were detected in this particle by EPMA, this particle was divided into a few fragments, as shown in its SEI after ATR-FTIR imaging (see the right inset in Fig. 4), which contained carbon, sulfur, and other elements by EPMA after ATR-FTIR imaging. As the
X-ray spectrum of particle \#33 was obtained from the center of the particle before ATR-FTIR imaging, only $\mathrm{NaNO}_{3}$ species were detected by low- $Z$ particle EPMA, whereas the ATR-FTIR signals were obtained from a large area, i.e. $\sim 5.8 \mu \mathrm{m}$ diameter (Jung et al., 2010), including the central $\mathrm{NaNO}_{3}$ and surrounding particles. The internally mixed particles showed carbonyl and aliphatic $\mathrm{CH}$ peaks, which are probably organic substances from sea water.

Six $\mathrm{NaNO}_{3}$-containing particles, such as particles \#1, 8, 54, 66, 73, and 104 (see Table S1 of the Supplement), were internally mixed with silicate minerals. As an example, the ATR-FTIR spectrum, X-ray spectrum and elemental atomic concentrations, and SEIs of particle \#54 are presented in Fig. $4 \mathrm{c}$ and $\mathrm{f}$ and the insets, respectively. Its major elements were $\mathrm{O}(52 \%), \mathrm{N}(23 \%), \mathrm{Na}(17 \%), \mathrm{C}(5 \%)$, and $\mathrm{Ca}(3 \%)$, suggesting that particle \#33 is a $\mathrm{NaNO}_{3}$ particle with carbonaceous and $\mathrm{Ca}$-containing species. The faint, dark circle surrounding bright crystalline particles, as observed in its SEI obtained before ATR-FTIR imaging, indicates that it was collected as a water droplet containing $\mathrm{NaNO}_{3}$ species, which was confirmed by the presence of 
IR peaks of water at 1634 and $\sim 3301 \mathrm{~cm}^{-1}$ and of crystalline $\mathrm{NaNO}_{3}$ at 831,1349 , and $1788 \mathrm{~cm}^{-1}$. In addition, the ATR-FTIR spectrum shows the presence of inorganic carbonate at 862 and $1400 \mathrm{~cm}^{-1}$, nitrite at $1250 \mathrm{~cm}^{-1}$, sulfate at $1110 \mathrm{~cm}^{-1}$, and montmorillonite at $1013 \mathrm{~cm}^{-1}$. These $\mathrm{NaNO}_{3}$-containing particles mixed with silicate minerals, constituting a significant portion of $\mathrm{NaNO}_{3}$-containing particles (i.e., 6 among overall 33 particles), appear to be due to coagulation between particles of marine and soil origins probably through cloud processing, which was also reported by other studies (Zhang et al., 2003; Sullivan et al., 2007b; Sobanska et al., 2012).

\subsection{Silicate particles}

Among the 109 particles examined, the number of silicate particles is 24 , where $11,8,3,2,2$, and 1 particle contain montmorillonite, quartz, feldspars, cristobalite, muscovite, and vermiculite, respectively. Although low- $Z$ particle EPMA can provide the elemental concentrations to identify silicate particles, the speciation of silicate particles can be determined unambiguously by the combined use of their ATR-FTIR spectral data (Jung et al., 2010). For this Asian dust particle sample, the major silicates were montmorillonite and quartz. A previous study reported that montmorillonite and calcite are characteristic, major minerals for Chinese loess soils, whereas quartz and feldspars are characteristic of Chinese desert soils (Malek et al., 2011).

\subsubsection{Silicate particles without water}

Among 24 silicate particles, 14 particles were mineral particles that did not contain a considerable amount of water (Table 1). As a typical example, the ATR-FTIR spectrum, $\mathrm{X}$-ray spectrum and elemental atomic concentrations, and SEIs of particle \#24 are shown in Fig. 5a and d and the insets, respectively. Its major elements were $\mathrm{O}(60 \%), \mathrm{Si}$ $(15 \%), \mathrm{Al}(14 \%), \mathrm{C}(5 \%), \mathrm{K}(3 \%)$, and $\mathrm{Na}(1 \%)$, suggesting that particle \#24 is an aluminosilicate particle with carbonaceous species. Its bright and angular SEI before the ATR-FTIR measurement indicates that it is a crystalline solid mineral. Based on its ATR-FTIR spectral data, particle \#24 was clearly identified as muscovite mixed internally with minor carbonate and organic species; i.e. IR peaks at 753,821 , $926,1006,1160$, and $3630 \mathrm{~cm}^{-1}$ are for muscovite (Jung et al., 2010), $1400 \mathrm{~cm}^{-1}$ for carbonate, and $\sim 1620 \mathrm{~cm}^{-1}$ for carboxylic ion. The IR peak at $3630 \mathrm{~cm}^{-1}$ was assigned to crystal $\mathrm{OH}$ in muscovite, and no water was present in this particle. During long-range transport, this silicate particle did not experience chemical modification. Among the 14 particles, seven particles contained swelling clay minerals, i.e. montmorillonite, and nine contained nonswelling quartz or muscovite.

\subsubsection{Silicate particles mixed with nitrate, organic, and water}

Ten silicate particles were observed to be mixed with nitrate, organic, and water, where five particles contain swelling clay minerals, such as montmorillonite and vermiculite, and the other five contained nonswelling minerals, such as cristobalite, quartz, and feldspar (Table 1). The nonswelling silicate particles are also mixed with water as well as nitrate and organic. As an example of swelling silicate particles mixed with nitrate, organic, and water, the ATR-FTIR spectrum, X-ray spectrum and elemental atomic concentrations, and SEIs of particle \#40 are shown in Fig. 5b and e and the insets, respectively. Its elemental concentrations were $\mathrm{O}$ (55\%), Si (10\%), C (12\%), N (7\%), Al (6\%), Ca (4\%), $\mathrm{Mg}(4 \%)$, and $\mathrm{Fe}(2 \%)$, suggesting that particle \#40 is an aluminosilicate with nitrate and carbonaceous species. This particle was collected as a water droplet because its SEI before ATR-FTIR imaging appeared dark and circular, and two crystalline particles were observed inside the dark circle. Based on its ATR-FTIR spectral data, the major species of particle \#40 is vermiculite supported by its IR peaks at 753, $833,910,1006$, and $1158 \mathrm{~cm}^{-1}$ (Jung et al., 2010), and minor components are carbonate ( 866 and $1404 \mathrm{~cm}^{-1}$ ), nitrate (824 and $1367 \mathrm{~cm}^{-1}$ ), water $\left(1639\right.$ and $\left.3305 \mathrm{~cm}^{-1}\right)$, and organics $\left(1618 \mathrm{~cm}^{-1}\left(\mathrm{COO}^{-}\right)\right.$and $\left.1705 \mathrm{~cm}^{-1}(\mathrm{C}=\mathrm{O})\right)$. Vermiculite is one of the swelling clay minerals (Jung et al., 2010). This particle might have picked up water during long-range transport, and nitrate was formed from the heterogeneous reaction of carbonate and $\mathrm{NO}_{\mathrm{x}} / \mathrm{HNO}_{3}$. Water-soluble organic species also appear to have been entrained in this particle during long-range transport.

As an example of nonswelling silicate particles mixed with nitrate, organic, and water, the ATR-FTIR spectrum, X-ray spectrum and elemental atomic concentrations, and SEIs of particle \#45 are shown in Fig. $5 \mathrm{c}$ and $\mathrm{f}$ and the insets, respectively. Its major elements were $\mathrm{O}(58 \%), \mathrm{Si}(20 \%), \mathrm{Al}(7 \%)$, $\mathrm{K}(5 \%), \mathrm{C}(6 \%)$, and $\mathrm{N}(2 \%)$, suggesting that particle \#45 is an aluminosilicate with carbonaceous and nitrate species. This particle was collected as a water droplet because its SEI showed a dark area surrounding an angular particle. ATRFTIR spectral data revealed the major species of particle \#45 to be K-feldspar $\left(\mathrm{KAlSi}_{3} \mathrm{O}_{8}\right)$ supported by its IR peaks at 993, 1086, and $1109 \mathrm{~cm}^{-1}$ (Jung et al., 2010) and the minor species to be carbonate ( 866 and $\left.1410 \mathrm{~cm}^{-1}\right)$, water $(1639$ and $\left.3314 \mathrm{~cm}^{-1}\right)$, and organic $\left(1623 \mathrm{~cm}^{-1}\left(\mathrm{COO}^{-}\right)\right)$. As the atomic concentration of nitrogen was only $2 \%$ based on Xray analysis, the IR peak of nitrate appeared to be too small to be differentiated from carbonate peak.

Only a few studies on the reactivity of silicate particles have been performed in laboratories. Of these, the major focus has been on the ability of the adsorption and/or absorption of water by silicate particles because the water uptaken by silicate particles is believed to enhance their reactivity. Indeed, the water uptake was reported to be high 


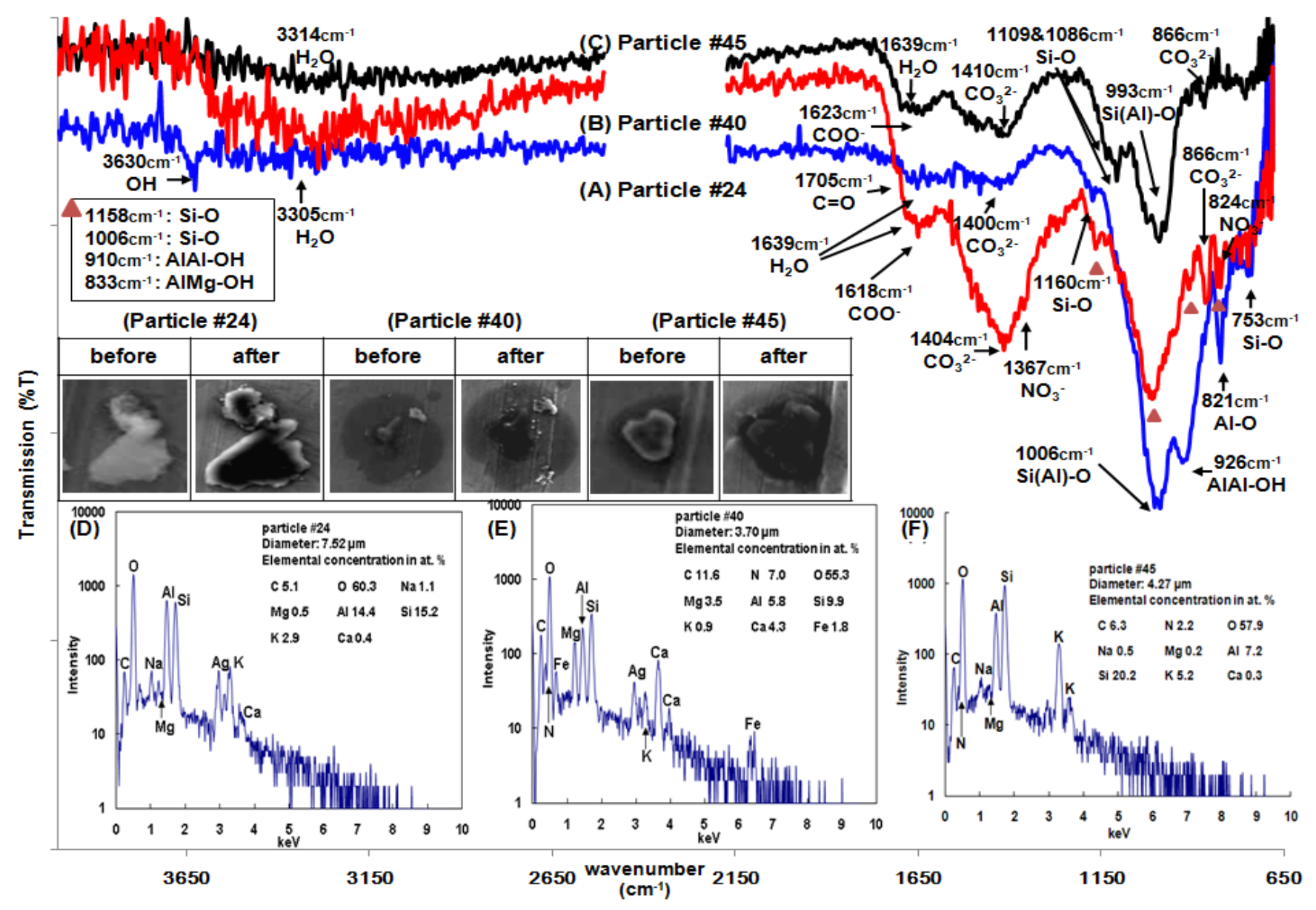

Fig. 5. ATR-FTIR and X-ray spectra of typical silicate particles and SEIs of particles obtained before and after ATR-FTIR imaging. The data for the $2200-2530 \mathrm{~cm}^{-1}$ region where atmospheric $\mathrm{CO}_{2}$ peaks are present were deleted for clarity.

for the swelling clay minerals (Frinak et al., 2005; Schuttlefield et al., 2007; Herich et al., 2009), and a swelling silicate mineral, i.e. Na-montmorillonite, can contain approximately $20 \%$ water and $30 \% \mathrm{HNO}_{3}$ by weight, even at $44 \% \mathrm{RH}$ (Mashburn et al., 2006). The current single-particle mineralogical field work, in which both the mineral types of silicate particles and the presence of water can be clearly identified, shows that the water uptake is not strongly dependent on the swelling property of the silicate minerals because some nonswelling silicates contain water, whereas some swelling minerals do not. In the present study, all water-containing, either swelling or nonswelling, silicate particles are also mixed with a small amount of nitrate, carbonate, and organic components with the presence of calcium, strongly suggesting that the water uptake of Asian dust silicate particles was governed by the original presence of $\mathrm{CaCO}_{3}$ species in the silicate minerals (see Table S1 in the Supplement). In the laboratory, the water uptake and reactivity of pure swelling and/or nonswelling silicate particles were examined. The swelling minerals showed higher water uptake and reactivity. In this Asian dust sample, the $\mathrm{CaCO}_{3}$ moiety originally present in silicate mineral particles appears to be more important for their aging than their silicate mineral type. A previous study reported that many silicate particles of Chinese source soils were mixed internally with $\mathrm{CaCO}_{3}$ (Malek et al., 2011). In particular, for the Chinese loess soils collected in Louchuan and Ganquan it was observed that more than $90 \%$ of montmorillonite, muscovite, and illite contained carbonate minerals as a minor mineral, and more than $60 \%$ of quartz, cristobalite, and feldspars did. A similar observation was also made for silty soils from the Chinese loess plateau, in which the clay minerals were claimed to be aggregated with nanosized calcite covering the silt-sized minerals (Jeong, 2008; Jeong and Chun, 2006).

\subsection{Miscellaneous particles}

Eleven particles were classified as miscellaneous, which included four carbonaceous particles, two fly ash, two $\mathrm{Mg}$ containing particles, two Fe-containing particles, and one aluminum oxide particle (see Table 1 and Table S1 in the Supplement). 


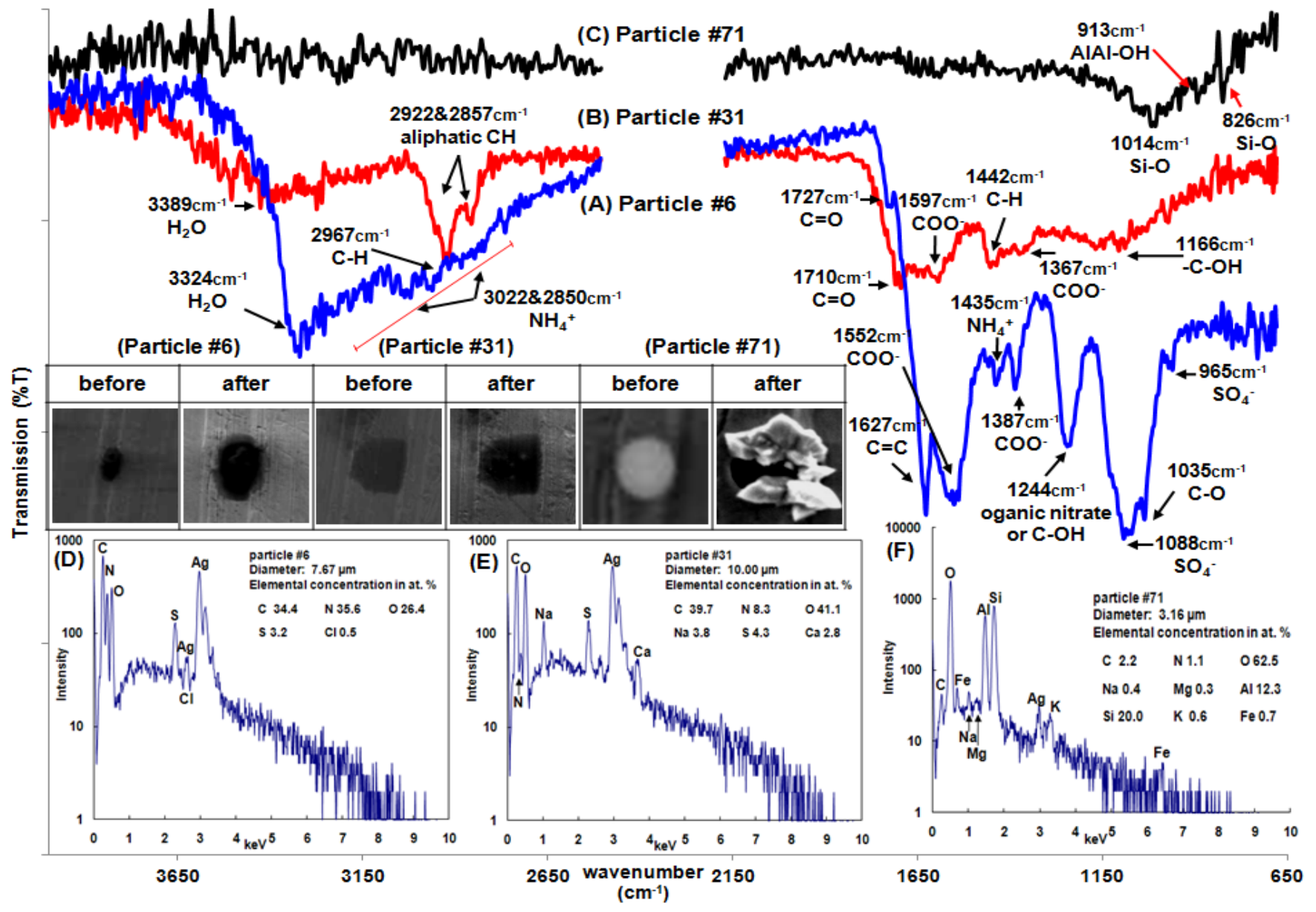

Fig. 6. ATR-FTIR and X-ray spectra of miscellaneous particles and SEIs of particles obtained before and after ATR-FTIR imaging. The data for the $2200-2530 \mathrm{~cm}^{-1}$ region where atmospheric $\mathrm{CO} 2$ peaks are present were deleted for clarity.

\subsubsection{Carbonaceous particles}

The ATR-FTIR spectrum, X-ray spectrum and elemental atomic concentrations, and SEIs of carbonaceous particle \#6 are shown in Fig. 6a and d and the insets, respectively, and of carbonaceous particle \#31 in Fig. $6 \mathrm{~b}$ and e and the insets, respectively. Particle \#6 appeared dark and round in its SEI (Fig. 6d), indicating that it was collected as a water droplet. Its elemental concentrations based on $\mathrm{X}$-ray analysis were $\mathrm{C}(34 \%), \mathrm{N}(36 \%), \mathrm{O}(26 \%), \mathrm{S}(3 \%)$, and $\mathrm{Cl}(1 \%)$, suggesting that it is a water-soluble organic aerosol (WSOA). Its ATR-FTIR spectrum of particle \#6 (Fig. 6a) revealed the presence of various types of functional groups, such as carbonyl carbon $(\mathrm{C}=\mathrm{O})$ at $1727 \mathrm{~cm}^{-1}$, carbon-carbon double bond $(\mathrm{C}=\mathrm{C})$ at $1627 \mathrm{~cm}^{-1}$, carboxylate ion $\left(\mathrm{COO}^{-}\right)$at 1387 and $1552 \mathrm{~cm}^{-1}$, organic nitrates $\left(\mathrm{CONO}_{2}\right)$ or $\mathrm{C}-\mathrm{O}-\mathrm{H}$ bending at $1244 \mathrm{~cm}^{-1}, \mathrm{C}-\mathrm{O}$ stretch at $1035 \mathrm{~cm}^{-1}$, ammonium ion $\left(\mathrm{NH}_{4}^{+}\right)$at 1435 and $2850-3022 \mathrm{~cm}^{-1}$, sulfate $\left(\mathrm{SO}_{4}^{2-}\right)$ at 965 and $1088 \mathrm{~cm}^{-1}, \mathrm{C}-\mathrm{H}$ at $2967 \mathrm{~cm}^{-1}$, and water at $1630-1640$ and $3324 \mathrm{~cm}^{-1}$, indicating that particle \#6 is a WSOA mixed with $\left(\mathrm{NH}_{4}\right)_{2} \mathrm{SO}_{4}$. As the content of nitrogen is much larger than that of sulfur, most of the nitrogen probably exists as organic nitrates. Particle \#31 appeared dark and round with elemental concentrations of $\mathrm{C}(40 \%), \mathrm{N}(8 \%), \mathrm{O}(41 \%), \mathrm{Na}$ (4\%), S (4\%), and $\mathrm{Ca}(3 \%)$ (Fig. 6e), indicating that it is also a WSOA. However, its ATR-FTIR spectrum is different from that of particle \#6 as shown in Fig. 6a and b. The ATR-FTIR spectrum of particle \#31 showed very strong aliphatic C-H IR absorption peaks at 1442, 2857, and $2922 \mathrm{~cm}^{-1}$ as well as strong $\mathrm{C}=\mathrm{O}$ at $1710 \mathrm{~cm}^{-1}, \mathrm{COO}^{-}$at 1367 and $1597 \mathrm{~cm}^{-1}$,$\mathrm{C}-\mathrm{OH}$ at $1166 \mathrm{~cm}^{-1}$, and water at $3389 \mathrm{~cm}^{-1}$. The two watersoluble, secondary organic aerosols should be formed differently, but the combined use of X-ray and ATR-FTIR spectral data could not clearly identify the organic molecular species even on a single-particle basis. Among the four carbonaceous particles, particle \#37 is also a WSOA, and particle \#86 is elemental carbon because its carbon content is largest based on $\mathrm{X}$-ray analysis and no IR peak is detected in its ATR-FTIR spectrum. 


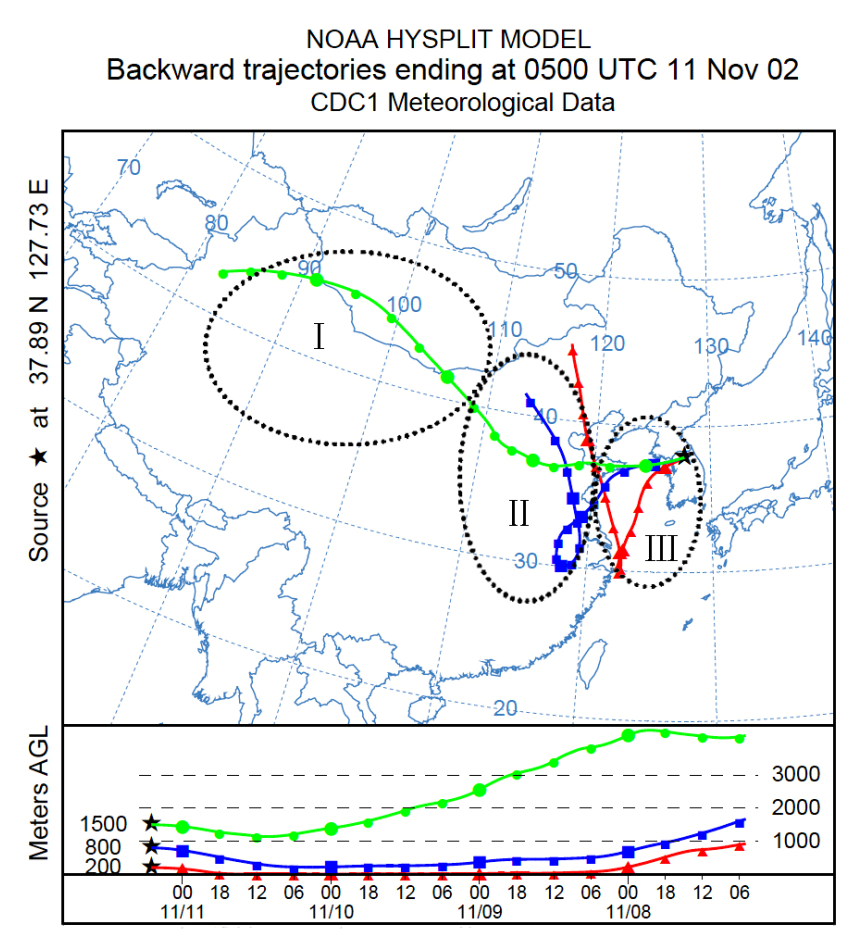

Fig. 7. 96 h air mass backward trajectories for the samples collected on 11 November 2002. The dotted circles give the rough range of different transport regions of the Asian dust: Region I represents the dust source; Region II represents the industrialized and residential area; Region III includes the Yellow Sea, the East China Sea, and the Korean peninsula.

\subsubsection{Fly ash particles}

Two particles were observed as fly ash particles. For example, particle \#71 appeared bright and circular. This is characteristic for fly ash particles generated during hightemperature combustion processes. Its elemental concentrations based on X-ray analysis were C $(2 \%), \mathrm{N}(1 \%), \mathrm{O}$ (63\%), $\mathrm{Al}(12 \%)$, and $\mathrm{Si}(20 \%)$, and its ATR-FTIR spectrum (Fig. 6c) shows silicate peaks (Si-O) at 826, 914, and $1014 \mathrm{~cm}^{-1}$, indicating that this is an aluminosilicate fly ash particle. These fly ash particles are of anthropogenic origin, and thus they must be entrained during long-range transport over the industrialized areas of China and/or Korea.

\subsection{Possible aging process of Asian dust particles during long-range transport}

When Asian dust storms move from the Taklimakan Desert (China) and/or the Gobi Desert (China/Mongolia) to the Korean Peninsula, many of the dust particles are aged through heterogeneous reactions with acidic gases (e.g. $\mathrm{SO}_{2}, \mathrm{NO}_{2}$, $\mathrm{H}_{2} \mathrm{SO}_{4}$, and $\mathrm{HNO}_{3}$ ) or through internally mixing with other chemical species by condensation, coagulation, and cloud processing (Manktelow et al., 2010; Formenti et al., 2011). The air mass backward trajectory analysis and the single- particle measurements by the combined use of low- $Z$ particle EPMA and ATR-FTIR imaging can provide strong implications about the aging process of Asian dust particles during long-range transport. As shown in $96 \mathrm{~h}$ backward air mass trajectories obtained at receptor heights of $200 \mathrm{~m}, 800 \mathrm{~m}$, and $1500 \mathrm{~m}$ (Fig. 7), the Asian dust particles passed over three different regions before being collected in ChunCheon, Korea. The first (Region I in Fig. 7) is the dust source region where the Asian dust storm event originated, the second (Region II) is the industrialized and residential region of central and eastern China, and the third region (Region III) includes the Yellow Sea, the East China Sea, and the mainland of Korea.

In the source region, the Asian dust storm injected immense quantities of dust particles into the atmosphere. These particles, mostly comprised of minerals such as calcite, quartz, montmorillonite, feldspars, cristobalite, muscovite, and vermiculite (as shown in Figs. 3 and 5 and Table S1), were transported by strong westerly winds to central and eastern China, where many types of air pollutants (e.g. $\mathrm{SO}_{2}$, $\mathrm{NO}_{2}, \mathrm{O}_{3}, \mathrm{NH}_{3}$, soot, and organic compounds) from anthropogenic activities were emitted (Xue, et al., 2013). The Asian dust particles would meet pollutants in the atmosphere of Region II and heterogeneous chemical reactions would occur (Huang et al., 2010). Reactive gases (e.g. $\mathrm{SO}_{2}, \mathrm{NO}_{2}$, etc.) were likely adsorbed on some of the dust particles and then oxidized to their acidic forms; or the acidic gases (e.g. $\mathrm{HNO}_{3}$ and $\mathrm{H}_{2} \mathrm{SO}_{4}$ ) or their ammonium salts (e.g. $\mathrm{NH}_{4} \mathrm{NO}_{3}$ and $\left.\left(\mathrm{NH}_{4}\right)_{2} \mathrm{SO}_{4}\right)$ were directly adsorbed on the dust particles. When the acids were formed/adsorbed on the dust particles, they could be fully or partially neutralized by the alkaline species (e.g, $\mathrm{CaCO}_{3}$ ) or by ambient $\mathrm{NH}_{3}$. The mixing extent and reaction process mainly depend on their transport pathway of Asian dust particles, concentrations of pollutant precursors, meteorological conditions, etc. (Sullivan et al., 2007a).

When genuine and reacted dust particles carried by the air masses passed over Region III, they would be mixed with sea salt, and, in the marine air with high humidity, the dust particles are expected to be more easily wetted by $\mathrm{H}_{2} \mathrm{O}$ to form thin water films on the surface, resulting in more efficient transformation of sulfur dioxide to sulfate and nitrogen oxides to nitrate. Formation of sulfate and nitrate is also closely related to the dust composition. Sulfate and nitrate formation was favored for $\mathrm{CaCO}_{3}, \mathrm{CaMg}\left(\mathrm{CO}_{3}\right)_{2}$, and silicate particles containing calcium compared to other mineral particles. Some silicate particles without calcium, e.g. particles \#21, 24, 67, 93, 97, and 101, did not experience chemical modification.

As can be seen in Tables 1 and S1, nitrate formation on carbonates is more favorable than sulfate formation because $\mathrm{Ca}\left(\mathrm{NO}_{3}\right)_{2}$ is more hygroscopic than $\mathrm{CaSO}_{4}$ and the formation rate of $\mathrm{NO}_{3}^{-}$by oxidation of nitrogen oxides is faster than that of $\mathrm{SO}_{4}^{2-}$ by oxidation of sulfur oxides. For most 
of Ca- and silicate-containing particles and even for fly ash and Fe-containing particles, ATR-FTIR nitrate and X-ray nitrogen peaks were detected. The formation of nitrates from $\mathrm{CaCO}_{3}$ would significantly enhance the uptake of water and water-soluble species, resulting in a positive feedback until all $\mathrm{CaCO}_{3}$ were transformed to $\mathrm{Ca}\left(\mathrm{NO}_{3}\right)_{2}$ (Formenti, et al., 2011). The $\mathrm{CaCl}_{2}$-containing particles (particles \#43, 48 , and 52 in Fig. 2) should be generated in this third region by the reaction of $\mathrm{CaCO}_{3} / \mathrm{CaMg}\left(\mathrm{CO}_{3}\right)_{2}$-containing particles with $\mathrm{HCl}$, as suggested by Sullivan et al. (2007a, b) and Tobo et al. (2010). The gaseous $\mathrm{HCl}$ was likely produced from chemically aged sea salt particles suspended in the marine boundary layer over the Yellow Sea and the East China Sea. Given that no genuine sea salt particle was found and the majority of reacted sea salt particles were $\mathrm{NaNO}_{3}$-containing, the $\mathrm{Cl}$ depletion from sea salts would be caused mostly by the uptake of $\mathrm{HNO}_{3}\left(\right.$ or $\mathrm{NO}_{\mathrm{x}}$ ) rather than that of $\mathrm{H}_{2} \mathrm{SO}_{4}\left(\right.$ or $\mathrm{SO}_{2}$ ). $\mathrm{HCl}(\mathrm{g})$ released from the acidified sea salt particles would deposit onto mineral dust particles, which acted as nonnegligible carriers of chloride (Sullivan et al., 2007b). Some reacted (aged) individual particles contained both nitrate and sulfate, and a few even contained sulfate, nitrate, and $\mathrm{Cl}$ simultaneously (e.g. particles \#2, 16, 82, 85, and 109), suggesting that they might experience a complicated aging process.

It was not surprising to encounter internal mixtures of mineral dust and totally reacted sea salt particles, e.g. particles $\# 1,8,54,66,73$, and 104, because the Asian dust particles were collected inland after they traveled over the marine air. Apart from particle-to-particle collision, in-cloud processing was regarded as a major route for particle agglomeration (Andreae et al., 2008). Many particles examined in this work contained minor quantities of organic compounds and/or aqueous organic coatings (see Table 1), suggesting that the organic matter was from WSOA or formed by aqueous-phase processing during transport of the dust particles in the atmosphere. WSOA, the majority of which consists of oxygenated organic aerosol (OOA), such as carboxylic acids, aldehydes, ketones, alcohols, and peroxides, was reported to be approximately $20-35 \%$ of the organic carbon fraction (Pathak et al., 2011). Dicarboxylic acids were possibly included as they are typically the most dominant fraction of WSOA, and oxalic and malonic acids were found to be mixed with mineral dust and aged sea salt particles during an Asian dust storm event (Sullivan and Prather, 2007). However, both the low- $Z$ particle EPMA and ATR-FTIR imaging techniques could not provide explicit compositional information on the organic matter internally mixed with $\mathrm{Ca}$ - and $\mathrm{NaNO}_{3}$-containing and silicate particles.

\section{Summary and conclusions}

This study examined aged Asian dust particles collected during an Asian dust storm event on 11 November 2002 in Korea using low- $Z$ particle EPMA and ATR-FTIR imaging in combination. Among the 109 particles analyzed, the most abundant particle type was Ca-containing (38\%) followed by $\mathrm{NaNO}_{3}$-containing $(30 \%)$, silicate $(22 \%)$, and miscellaneous particles $(10 \%)$. Among overall $41 \mathrm{Ca}$-containing particles, the number of particles containing nitrate, sulfate, both, ACC, and $\mathrm{CaCl}_{2}$ were 10, 8, 14, 4, and 3, respectively. ACC particles were encountered in this Asian dust sample for the first time, and the presence of $\mathrm{CaCl}_{2}$ particles probably converted from $\mathrm{CaCO}_{3}$ for the inland field sample was also observed. Thirty-three $\mathrm{NaNO}_{3}$-containing particles, which are reaction products of sea salt and $\mathrm{NO}_{\mathrm{x}} / \mathrm{HNO}_{3}$, were observed, whereas no genuine sea salt was encountered, indicating that sea salt particles are more reactive than $\mathrm{CaCO}_{3}$ particles. Among the 24 silicate particles, $42 \%$ of them (including swelling minerals, such as montmorillonite and vermiculite, and nonswelling ones, such as feldspar and quartz) were mixed with nitrate, organic, and water. The reactivity of silicate particles appear to be governed by the presence of internally mixed minor $\mathrm{CaCO}_{3}$ moiety, rather than the swelling property of silicate particles.

In conclusion, this study provided detailed information on the physicochemical characteristics of aged individual Asian dust particles, which experienced extensive chemical modification during long-range transport, by the combined use of two single-particle analytical techniques, and using this analytical methodology it was clearly shown that internal mixing states of the aged particles are highly complicated.

\section{Supplementary material related to this article is available online at: http://www.atmos-chem-phys.net/13/ 3463/2013/acp-13-3463-2013-supplement.pdf.}

Acknowledgements. This study was supported by Basic Science Research Programs through the National Research Foundation of Korea (NRF) funded by the Ministry of Education, Science, and Technology (Grant 2012R1A2A1A05026329), and by Inha University. Also, we gratefully acknowledge support provided from the National Natural Science Foundation of China (NSFC) (Grant 21177078) and the NSFC-NRF Scientific Cooperation Program (Grant 2012K1A2B1A03000431, 41211140241).

Edited by: J. G. Murphy

\section{References}

Addadi, L., Raz, S., and Weiner, S.: Taking advantage of disorder: Amorphous calcium carbonate and its roles in biomineralization, Adv. Mater., 15, 959-970, 2003.

Allen, D. T., Palen, E. J., Haimov, M. I., Hering, S. V., and Young, J. R.: Fourier transform infrared spectroscopy of aerosol collected in a low pressure impactor (LPI/FTIR): method development and field calibration, Aerosol Sci. Technol., 21, 325-342, 1994.

Allen, H. C., Mecartney, M. L., and Hemminger, J. C.: Minimizing transmission electron microscopy beam damage during the study 
of surface reactions on sodium chloride, Microsc. Microanal., 4, 23-33, 1998.

Andreae, M. O. and Rosenfeld, D.: Aerosol-cloud-precipitation interactions. Part 1. The nature and sources of cloud-active aerosols, Earth-Sci. Rev., 89, 13-41, 2008.

Arimoto, R., Zhang, X. Y., Huebert, B. J., Kang, C. H., Savoie, D. L., Prospero, J. M., Sage, S. K., Schloesslin, C. A., Khaing, H. M., and Oh, S. N.: Chemical composition of atmospheric aerosols from Zhenbeitai, China, and Gosan, South Korea, during ACE-Asia, J. Geophys. Res., 109, D19S04, doi:10.1029/2003JD004323, 2004.

Baker, A. R., Kelly, S. D., Biswas, K. F., Witt, M., and Jickells, T. D.: Atmospheric deposition of nutrients to the Atlantic Ocean, Geophys. Res. Lett., 30, 2296-2299, 2003.

Bergstrom, R. W., Pilewskie, P., Russell, P. B., Redemann, J., Bond, T. C., Quinn, P. K., and Sierau, B.: Spectral absorption properties of atmospheric aerosols, Atmos. Chem. Phys., 7, 5937-5943, doi:10.5194/acp-7-5937-2007, 2007.

Beniash, E., Aizenberg, J., Addadi, L., and Weiner, S.: Amorphous calcium carbonate transforms into calcite during sea urchin larval spicule growth, Proc. R. Soc. Lond. B, 461-465, 1997.

Cabaniss, S. E., Leenheer, J. A., and McVey, I. F.: Aqueous infrared carboxylate absorbances: aliphatic di-acids, Spectrochim. Acta A, 54, 449-458, 1998.

Chung, Y., Kim, H., Dulam, J., and Harris, J.: On heavy dustfall observed with explosive sandstorms in Chongwon-Chongju, Korea in 2002, Atmos. Environ., 37, 3425-3433, 2003.

Cottle, P., Strawbridge, K., McKendry, I., O’Neill, N., and Saha, A.: A pervasive and persistent Asian dust event over North America during spring 2010: lidar and sunphotometer observations, Atmos. Chem. Phys. Discuss., 12, 30589-30618, doi:10.5194/acpd-12-30589-2012, 2012.

Coury, C. and Dillner, A. M.: A method to quantify organic functional groups and inorganic compounds in ambient aerosols using attenuated total reflectance FT-IR pectroscopy and multivariate chemometric techniques, Atmos. Environ., 5923-5932, 2008.

Formenti, P., Schutz, L., Balkanski, Y., Desboeufs, K., Ebert, M., Kandler, K., Petzold, A., Scheuvens, D., Weinbruch, S., and Zhang, D.: Recent progress in understanding physical and chemical properties of African and Asian mineral dust, Atmos. Chem. Phys., 11, 8231-8256, doi:10.5194/acp-11-8231-2011, 2011.

Frinak, E. K., Mashburn, C. D., Tolbert, M. A., and Toon, O. B.: Infrared characterization of water uptake by low-temperature Namontmorillonite: Implications for Earth and Mars, J. Geophys. Res., 110, D09308, doi:10.1029/2004JD005647, 2005.

Geng, H., Park, Y.-M., Hwang, H., Kang, S., and Ro, C.-U.: Elevated nitrogen-containing particles observed in Asian dust aerosol samples collected at the marine boundary layer of the Bohai Sea and the Yellow Sea, Atmos. Chem. Phys, 9, 6933-6947, doi:10.5194/acp-9-6933-2009, 2009.

Geng, H., Kang, S., Choel, M., Kim, H., and Ro, C.-U.: Characterization of individual submicrometer aerosol particles collected in Incheon, Korea, by quantitative transmission electron microscopy energy-dispersive X-ray spectrometr, J. Geophys. Res, 115, D15306, doi:10.1029/2009JD013486, 2010.

Gibson, E. R., Hudson, P. K., and Grassian, V. H.: Physicochemical properties of nitrate aerosols: Implications for the atmosphere, J. Phys. Chem., 110A, 11785-11799, 2006.
Goldstein, J. I., Newbury, D. E., Joy, D. C., Lyman, C., Echlin, P., Lifshin, E., Sawyer, L., and Michael, J.: Scanning electron microscopy and X-ray microanalysis, 3rd Edn.. Kluwer-Plenum, New York, USA, 2003.

Griffiths, P. R. and de Haseth, J. A.: Fourier transform infrared spectrometry, 2nd Edn., John Wiley \& Sons, Inc., Hoboken, New Jersey, 2007.

Gysel, M., Weingartner, E., and Baltensperger, U.: Hygroscopicity of aerosol particles at low temperatures. 2. Theoretical and experimental hygroscopic properties of laboratory generated aerosols, Environ. Sci. Technol., 36, 63-68, 2002.

Hay, M. B. and Myneni, S. C. B.: Structural environments of carboxyl groups in natural organic molecules from terrestrial systems. Part 1: Infrared spectroscopy, Geochim. Cosmochim. Acta, 71, 3518-3532, 2007.

Herich, H., Tritscher, T., Wiacek, A., Gysel, M., Weingartner, E., Lohmann, U., Baltensperger, U., and Cziczo D. J.: Water uptake of clay and desert dust aerosol particles at sub- and supersaturated water vapor conditions, Phys. Chem. Chem. Phys., 11, 7804-7809, 2009.

Hoffman, R. C., Laskin, A., and Finlayson-Pitts, B. J.: Sodium nitrate particles: physical and chemical properties during hydration and dehydration, and implications for aged sea salt aerosols, J. Aerosol Sci., 35, 869-887, 2004.

Hu, D., Qiao, L., Chen, J., Ye, X., Yang, X., Cheng, T., and Fang, W.: Hygroscopicity of inorganic aerosols: size and relative humidity effects on the growth factor. Aerosol Air Qual. Res., 10, 255-264, 2010.

Huang, K., Zhuang, G. S., Li, J. A., Wang, Q. Z., Sun, Y. L., Lin, Y. F., and Fu, J. S.: Mixing of Asian dust with pollution aerosol and the transformation of aerosol components during the dust storm over China in spring 2007, J. Geophys. Res., 115, D00K13, doi:10.1029/2009JD013145, 2010.

Huebert, B. J., Bates, T., Russell, P. B., Shi, G. Y., Kim, Y. J., Kawamura, K., Carmichael, G., and Nakajima, T.: An overview of ACE-Asia: Strategies for quantifying the relationships between Asian aerosols and their climatic impacts, J. Geophys. Res., 108, 8633-8652, 2003.

Hwang, H. and Ro, C.-U.: Single-particle characterization of four aerosol samples collected in ChunCheon, Korea, during Asian dust storm events in 2002, J. Geophys. Res, 110, D23201, doi:10.1029/2005JD006050, 2005.

Hwang, H. and Ro, C.-U.: Direct observation of nitrate and sulfate formations from mineral dust and sea-salts using low-Z particle EPMA, Atmos. Environ., 40, 3869-3880, 2006.

Hwang, H., Kim, H., and Ro, C.-U.: Single-particle characterization of aerosol samples collected before and during an Asian dust storm in Chuncheon, Korea, Atmos. Environ., 42, 8738-8746, 2008.

Jeong, G. Y.: Bulk and single-particle mineralogy of Asian dust and a comparison with its source soils, J. Geophys. Res., 113, D02208, doi:10.1029/2007JD008606, 2008.

Jeong, G. Y. and Chun, Y.: Nanofiber calcite in Asian dust and its atmospheric roles, Geophys. Res. Lett., 33, L24802, doi:10.1029/2006GL028280, 2006.

Jung, H.-J., Malek, M. A., Ryu, J., Kim, B., Song, Y., Kim, H., and Ro, C.-U.: Speciation of individual mineral particles of micrometer size by the combined use of attenuated total reflectance-fourier transform-infrared imaging and quantita- 
tive energy-dispersive electron probe X-ray microanalysis techniques, Anal. Chem., 82, 6193-6202, 2010.

Kim, H., Lee, M., Jung, H.-J., Eom, H.-J., Maskey, S., Ahn, K.-H., and Ro, C.-U.: Hygroscopic behavior of wet dispersed and dry deposited NaNO3 particles, Atmos. Environ., 60, 68-75, 2012.

Laskin A., Iedema M. J., and Cowin, J. P.: Quantitative timeresolved monitoring of nitrate formation in sea salt particles using a CCSEM/EDX single particle analysis, Environ. Sci. Technol., 36, 4948-4955, 2002.

Laskin, A., Wietsma, T. W., Krueger, B. J., and Grassian, V. H.: Heterogeneous chemistry of individual mineral dust particles with nitric acid: A combined CCSEM/EDX, ESEM, and ICP-MS study, J. Geophys. Res., 110, D10208, doi:10.1029/2004JD005206, 2005.

Li-Jones, X., Maring, H. B., and Prospero, J. M.: Effect of relative humidity on light scattering by mineral dust aerosol as measured in the marine boundary layer over the tropical Atlantic Ocean, J. Geophys. Res., 103, 31113-31121, 1998.

Liu, Y., Yang, Z., Desyaterik, Y., Gassman, P. L., Wang, H., and Laskin, A.: Hygroscopic behavior of substrate-deposited particles studied by micro-FT-IR spectroscopy and complementary methods of particle analysis, Anal. Chem., 80, 633-642, 2008.

Lu, P.-D., Wang, F., Zhao, L.-J., Li, W.-X., Li, X.-H., Dong, J.-L., Zhang, Y.-H., and Lu, G.-Q.: Molecular events in deliquescence and efflorescence phase transitions of sodium nitrate particles studied by Fourier transform infrared attenuated total reflection spectroscopy, J. Chem. Phys., 129, 104509. doi:10.1063/1.2973623, 2008.

Malek, M. A., Kim, B., Jung, H.-J., Song, Y.-C., and Ro, C.-U.: Single-particle mineralogy of Chinese soil particles by the combined use of low- $Z$ particle electron probe $X$-ray microanalysis and attenuated total reflectance-FT-IR imaging techniques, Anal. Chem., 83, 7970-7977, 2011.

Manktelow, P. T., Carslaw, K. S., Mann, G. W., and Spracklen, D. V.: The impact of dust on sulfate aerosol, $\mathrm{CN}$ and $\mathrm{CCN}$ during an East Asian dust storm, Atmos. Chem. Phys., 10, 365-382, doi:10.5194/acp-10-365-2010, 2010.

Mashburn, C. D., Frinak, E. K., and Tolbert, M. A.: Heterogeneous uptake of nitric acid on Na-montmorillonite clay as a function of relative humidity, J. Geophys. Res., 111, D15213, doi:10.1029/2005JD006525, 2006.

Max, J. J. and Chapados, C.: Infrared Spectroscopy of Aqueous Carboxylic Acids: Comparison between Different Acids and Their Salts, J. Phys. Chem. A, 108, 3324-3337, 2004.

Maxwell-Meier, K., Weber, R., Song, C., Orsini, D., Ma, Y., Carmichael, G. R., and Streets, D. G.: Inorganic composition of fine particles in mixed mineral dust-pollution plumes observed from airborne measurements during ACE-Asia, J. Geophys. Res., 109, D19S07, doi:10.1029/2003JD004464, 2004.

McNaughton, C. S., Clarke, A. D., Howell, S. G., Moore, K. G., Brekhovskikh, V., Weber, R. J., Orsini, D. A., Covert, D. S., Buzorius, G., Brechtel, F. J., Carmichael, G. R., Tang, Y. H., Eisele, F. L., Mauldin, R. L., Bandy, A. R., Thornton, D. C., and Blomquist, B.: Spatial distribution and size evolution of particles in Asian outflow: Significance of primary and secondary aerosols during ACE-Asia and TRACE-P, J. Geophys. Res., 109, D19S06, doi:10.1029/2003JD003528, 2004.

Nie, W., Wang, T., Xue, L. K., Ding, A. J., Wang, X. F., Gao, X. M., Xu, Z., Yu, Y. C., Yuan, C., Zhou, Z. S., Gao, R., Liu, X.
H., Wang, Y., Fan, S. J., Poon, S., Zhang, Q. Z., and Wang, W. X.: Asian dust storm observed at a rural mountain site in southern China: chemical evolution and heterogeneous photochemistry, Atmos. Chem. Phys., 12, 11985-11995, doi:10.5194/acp12-11985-2012, 2012.

Niemeyer, J., Chen, Y., and Bollag, J.-M.: Characterization of Humic Acids, Composts, and Peat by Diffuse Reflectance FourierTransform Infrared Spectroscopy, Soil Sci. Soc. Am. J., 56, 135 140, 1992.

Onishi, K., Kurosaki, Y., Otani, S., Yoshida, A., and Sugimoto, N.: Atmospheric transport route determines components of Asian dust and health effects in Japan, Atmos. Environ., 49, 94-102, 2012.

Pathak, R. K., Wang, T., Ho, K. F., and Lee, S. C.: Characteristics of summertime $\mathrm{PM}_{2.5}$ organic and elemental carbon in four major Chinese cities: Implications of high acidity for water-soluble organic carbon (WSOC), Atmos. Environ., 45, 318-325, 2011.

Paytan, A., Mackey, K. R. M., Chen, Y., Lima, I. D., Doney, S. C., Mahowald, N., Labiosa, R., and Post, A. F.: Toxicity of atmospheric aerosols on marine phytoplankton, Proc. Natl. Acad. Sci. USA, 106, 4601-4605, 2009.

Price, H. U., Jaffe, D. A., Cooper, O. R., and Doskey, P. V.: Photochemistry, ozone production, and dilution during long-range transport episodes from Eurasia to the northwest United States, J. Geophys. Res., 109, D23S13, doi:10.1029/2003JD004328, 2004.

Ro, C.-U., Osan, J., and Van Grieken, R.: Determination of low-Z elements in individual environmental particles using windowless EPMA, Anal. Chem., 71, 1521-1528, 1999.

Ro, C.-U., Kim, H., and Van Grieken, R.: An expert system for chemical speciation of individual particles using low- $Z$ particle electron probe X-ray microanalysis data, Anal. Chem., 76, 13221327, 2004.

Ro, C. -U., Hwang, H., Kim, H., Chun, Y., and Van Grieken, R.: Single-particle characterization of four Asian dust samples collected in Korea, using low- $Z$ particle electron probe $X$-ray microanalysis, Environ. Sci. Technol., 39, 1409-1419, 2005.

Roca, M., Zahardis, J., Bone, J., El-Maazawi, M., and Grassian, V. H.: $310 \mathrm{~nm}$ irradiation of atmospherically relevant concentrated aqueous nitrate solutions: nitrate production and quantum yields. J. Phys. Chem. A, 112, 13275-13281, 2008.

Russell, L. M., Maria, S. F., and Myneni, S. C. B.: Mapping organic coatings on atmospheric particles, Geophys. Res. Lett., 29, 1779 , doi:10.1029/2002GL014874, 2002.

Schuttlefield, J. D., Cox, D., and Grassian, V. H.: An investigation of water uptake on clays minerals using ATR-FTIR spectroscopy coupled with quartz crystal microbalance measurements, J. Geophys. Res., 112, D21303, doi:10.1029/2007JD008973, 2007.

Shi, Z., Zhang, D., Hayashi, M., Ogata, H., Ji, H., and Fujiie, Q.: Influences of sulfate and nitrate on the hygroscopic behaviour of coarse dust particles, Atmos. Environ., 42, 822-827, 2008.

Sobanska, S., Hwang, H., Choël, M., Jung, H.-J., Eom, H.-J., Kim, H., Barbillat, J., and Ro, C.-U.: Investigation of the chemical mixing state of individual Asian dust particles by the combined use of electron probe X-ray microanalysis and Raman microspectrometry, Anal. Chem., 84, 3145-3154, 2012.

Song, Y.-C., Ryu, J., Malek, M. A., Jung, H.-J., and Ro, C.-U.: Chemical speciation of individual airborne particles by the combined use of quantitative energy-dispersive electron probe X-ray microanalysis and attenuated total reflection Fourier transform- 
infrared imaging techniques, Anal. Chem., 82, 7987-7998, 2010.

Specht, C. H. and Frimmel, F. H.: An in situ ATR-FT-IR study on the adsorption of dicarboxylic acids onto kaolinite in aqueous suspensions, Phys. Chem. Chem. Phys., 3, 5444-5449, 2001.

Sullivan, R. C. and Prather, K. A.: Investigations of the diurnal cycle and mixing state of oxalic acid in individual particles in Asian aerosol outflow, Environ. Sci. Technol., 41, 8062-8069, 2007.

Sullivan, R. C., Guazzotti, S. A., Sodeman, D. A., and Prather, K. A.: Direct observations of the atmospheric processing of Asian mineral dust, Atmos. Chem. Phys., 7, 1213-1236, doi:10.5194/acp-7-1213-2007, 2007a.

Sullivan, R. C., Guazzotti, S. A., Sodeman, D. A., Tang, Y., Carmichael, G. R., and Prather, K. A.: Mineral dust is a sink for chlorine in the marine boundary layer, Atmos. Environ., 41, 7166-7179, 2007b.

Sullivan, R. C., Moore, M. J. K., Petters, M. D., Kreidenweis, S. M., Qafoku, O., Laskin, A., Roberts, G. C., and Prather, K. A.: Impact of particle generation method on the apparent hygroscopicity of insoluble mineral particles, Aerosol Sci. Technol., 44, 830-846, 2010.

Takahashi, Y., Higashi, M., Furukawa, T., and Mitsunobu, S.: Change of iron species and iron solubility in Asian dust during the long-range transport from western China to Japan, Atmos. Chem. Phys., 11, 11237-11252, doi:10.5194/acp-1111237-2011, 2011.

Thornton, J. A., Kercher, J. P., Riedel, T. P., Wagner, N. L., Cozic, J., Holloway, J. S., Dube, W. P., Wolfe, G. M., Quinn, P. K., Middlebrook, A. M., Alexander B., and Steven S. B.: A large atomic chlorine source inferred from mid-continental reactive nitrogen chemistry, Nature, 464, 271-274, 2010.

Tobo, Y., Zhang, D., Matsuki, A., and Iwasaka, Y.: Asian dust particles converted into aqueous droplets under remote marine atmospheric conditions, Proc. Natl. Acad. Sci. USA, 96, 3396-3403, 2010.

Uno, I., Eguchi, K., Yumimoto, K., Liu, Z., Hara, Y., Sugimoto, N., Shimizu, A., and Takemura, T.: Large Asian dust layers continuously reached North America in April 2010, Atmos. Chem. Phys., 11, 7333-7341, doi:10.5194/acp-11-7333-2011, 2011.

Vekemans, B., Janssens, K., Vincze, L., Adams, F., and Van Espen, P.: Analysis of X-ray spectra by iterative least squares (AXIL): New developments, X-Ray Spectrom., 23, 278-285, 1994.
Wang, G. H., Zhou, B. H., Cheng, C. L., Cao, J. J., Li, J. J., Meng, J. J., Tao, J., Zhang, R. J., and Fu, P. Q.: Impact of Gobi desert dust on aerosol chemistry of Xi' an, inland China during spring2009: differences in composition and size distribution between the urban ground surface and the mountain atmosphere, Atmos. Chem. Phys., 13, 819-835, doi:10.5194/acp-13-819-2013, 2013.

Watanabe, M., Yamasaki, A., Burioka, N., Kurai, J., Yoneda, K., Yoshida, A., Igishi, T., Fukuoka, Y., Nakamoto, M., Takeuchi, H., Suyama, H., Tatsukawa, T., Chikumi, H., Matsumoto, S., Sako, T., Hasegawa, Y., Okazaki, R., Horasaki, K., and Shimizu, E.: Correlation between Asian dust storms and worsening asthma in western Japan, Allerg. Int., 60, 267-275, 2011.

Weiner, S., Kalisman, Y. L, Raz, S., and Addadi, L.: Biologically formed amorphous calcium carbonate, Conn. Tiss. Res., 44, 214 218, 2003.

Worobiec, A., de Hoog, J., Osan, J., Szaloki, I., Ro, C.-U., and Van Grieken, R.: Thermal stability of beam sensitive atmospheric particles in electron probe microanalysis at liquid nitrogen temperature, Spectrochim. Acta B, 58, 851-865, 2003.

Xu, J., Bergin, M. H., Greenwald, R., Schauer, J. J., Shafer, M. M., Jaffrezo, J. L., and Aymoz, G.: Aerosol chemical, physical, and radiative characteristics near a desert source region of northwest China during ACE-Asia, J. Geophys. Res., 109, D19S03, doi:10.1029/2003JD004239, 2004.

Xue, W., Wang, J., Niu, H., Yang, J., Han, B., Lei, Y., Chen, H., and Jiang, C.: Assessment of air quality improvement effect under the National Total Emission Control Program during the Twelfth National Five-Year Plan in China, Atmos. Environ., 68, 74-81, 2013.

Zhang, D. Z., Iwasaka, Y., Shi, G. Y., Zang, J. Y., Matsuki, A., and Trochkine, D.: Mixture state and size of Asian dust particles collected at southwestern Japan in spring 2000, J. Geophys. Res. 108, 4760-4771, 2003.

Zhu, L., Chen, Y., Guo, L., and Wang, F.: Estimate of dry deposition fluxes of nutrients over the East China Sea: The implication of aerosol ammonium to non-sea-salt sulfate ratio to nutrient deposition of coastal oceans, Atmos. Environ., 69, 131-138, 2013.

Ziemba, L. D., Dibb, J. E., Griffin, R. J., Anderson, C. H., Whitlow, S. I., Lefer, B. L., Rappengluck, B., and Flynn, J.: Heterogeneous conversion of nitric acid to nitrous acid on the surface of primary organic aerosol in an urban atmosphere, Atmos. Environ. 44, 4081-4089, 2010. 